\title{
$¿$ DERECHOS DE LAS PERSONAS O DERECHOS DE LAS TEORÍAS?
}

\author{
Francisco CARPINTERo BeníteZ \\ Área de Filosofía del Derecho. Departamento de Derecho Público \\ Facultad de Derecho. Universidad de Cádiz \\ francisco.carpintero@uca.es
}

\section{INTRODUCCIÓN}

La palabra «persona» está vetada de hecho en amplios círculos académicos. La expresión misma de «derechos del hombre» ha sido sustituida por la de derechos humanos, porque parece que el sustantivo «hombre» compromete con los campos de la ontología y es preferible utilizar - puestos a evitar cargas ontológicas- el simple adjetivo de «humano» ${ }^{1}$. En estos ambientes la persona no existe en la reflexión sobre el Derecho, y Kelsen dejó establecido que la expresión persona jurídica es sólo una construcción doctrinal que es superflua en la descripción del derecho². Históricamente, esta negación del carácter personal del hombre ha ido vinculada al rechazo de la explicación racional de la justicia. Pero como es difícil mantener esta actitud durante mucho tiempo, los alemanes nos invadieron con sus versiones de la praktische Philosophie y los anglosajones no les anduvieron a la zaga, aunque con explicaciones utilitaristas que siguen más el English style que no a los seminoúmenos alemanes. Hemos llegado a una situación paradójica: hay que suponer que una teoría de la justicia ha de ser elaborada porque el ser humano posee un estatuto especial distinto al de las demás cosas; pero los hombres no somos los protagonistas de nuestros derechos, ya que únicamente permanecemos como puntos de atribu-

\footnotetext{
${ }^{1}$ En esta línea, Ollero nos indica que: «Resultará fácil constatar que buena parte de la resistencia de los juristas a reconocer como derechos proprio vigore los llamados derechos humanos es su opción — con frecuencia acrítica — por una perspectiva normativista, que simplifica la realidad presentando al Derecho como un sistema de normas, positivadas de una vez por todas y listas en consecuencia para una aplicación técnica sin ulteriores juicios de valor». Vid. A. OlLero, Derechos humanos entre la moral y el derecho, MéXICO, UNAM, 2007, p. 139.

2 Vid. H. Kelsen, Reine Rechtslebre, 2. ${ }^{a}$ ed., Wien, Franz Deuticke, 1960, $\$ 33$.
} 
ción de las virtualidades de una teoría sobre la justicia. Es un planteamiento parecido al de Kelsen, sólo que ahora las cosas — por hablar así- que son atribuidas a los seres humanos no son normas, sino resultados intelectuales de razonamientos que parten desde un equilibrio reflexivo o desde un diálogo realizado en condiciones intelectuales ideales.

El estudioso comprende las razones de quienes mantienen que el hombre tiene derechos porque es hombre. Desde el ángulo de una estricta ingenuidad científica, le resulta más difícil entender a los que afirman que no existe el deber (objetivo) de perseguir a los malhechores o de cumplir lo convenido. En lugar de afirmar este deber, autores que evitan el tema del hombre como hombre, es decir, como ser dotado de individualidad y de dignidad, elaboran tratados que pretenden tener la capacidad reflexiva suficiente como para situarse en el lugar de las exigencias más o menos inmediatas de los seres humanos. Lo procedente es preguntarse sobre la índole de estos estudios que parecen poseer capacidades normativas superiores a las de sus autores y destinatarios, porque ¿qué derecho especial puede alegar una teoría para exigir el asentimiento? Las explicaciones premodernas pretendían reproducir la realidad, y así procedieron Aristóteles, los Estoicos, Tomás de Aquino o Juan Duns Scoto. Pero, por motivos obvios, los empiristas no pueden lanzar esta pretensión. Este último hecho nos indica que detrás de la capacidad para exigir asentimiento opera algún factor oculto a simple vista que les otorga su capacidad para la imposición.

Puestos a poner el dedo sobre ese posible factor presente y silente, todo parece indicar que los autores de teorías unitarias sobre el Derecho recaban para sí una mayor audiencia porque han seguido el estilo del método científico de la Edad Moderna. Este momento histórico propuso una construcción intelectual (la Mecánica de Newton) que permitía acceder con seguridad al conocimiento del funcionamiento de la realidad física pero sin saber qué es esa realidad explicada: pues sabemos que existe la ley de la gravitación universal, pero no sabemos por qué ni para qué existe. Nos está vedado saber qué son en sí las realidades físicas o que es en sí el movimiento, pero la mentalidad más clásica entendía que de la mano del método nuevo sabemos cómo manipular una y otra, y si aún permanecen arcanos, desaparecerán inexorablemente con el desarrollo de la ciencia. Trasladado este modo de sentir a la teoría jurídica, habría que mantener que no sabemos lo que es el hombre, aunque sí podemos afirmar que nadie puede ser discriminado por razón de su sexo. Ciertamente, las actitudes filosóficas fueron distintas porque Hume fue francamente pesimista sobre las posibilidades del conocimiento humano, y Kant nos quiso hacer 
entrar por un camino más optimista, pero ambos filósofos entendieron que la explicación científica de Newton era la definitiva, y todo parece indicar que la validez de sus críticas ha ido unida a la validez del antiguo método científico.

La historia no ha seguido este camino newtoniano: las dificultades se fueron acumulando y, finalmente, Planck, Heisenberg y otros mostraron experimentalmente que no son ciertas las bases de aquella explicación mecánica. Estamos sufriendo una crisis de éxito, porque los físicos han aumentado notablemente sus conocimientos y aquellos moldes veteromecánicos se muestran incapaces de dar razón de lo que ahora comprueban los investigadores en sus laboratorios. Ante este panorama, un sector de la comunidad científica ha puesto la palanca de cambio en punto muerto y ha echado el freno de mano: no están los tiempos para dogmatismos. Los reflexionadores que proponen teorías sobre la justicia debieran seguir también esta actitud: porque a nosotros nos sucede lo mismo que a los físicos actuales: que no sabemos lo que es el hombre, pero sí sabemos positivamente y no de forma residual que los profesores debemos preparar las clases. Reitero que bastantes teóricos del Derecho siguen el estilo moderno de reflexionar, ya que quieren acceder a nuestra realidad mediante un constructo que ha de mediar entre los conocedores y lo que es conocido. Y lo más inmediato parece ser interrogarnos sobre la índole de este tipo de construcciones intelectuales.

Adelanto que la mecánica clásica, es decir, la mentalidad subyacente a este modo de hacer ciencia, es inesquivable para todos, y no solamente para quien comienza a estudiar física. Bergson entendía que la geometría es la metafísica natural de la razón humana ${ }^{3}$ y Heisenberg ampliaba esta tesis al mantener que la mecánica clásica forma parte igualmente de esta metafísica necesaria para los razonamientos científicos, no sólo en las ciencias naturales ${ }^{4}$. En efecto, el que estudia física ha de partir desde las enseñanzas de Newton y, desde ellas, ha de presentar a la mecánica cuán-

\footnotetext{
3 «Creer que los cuerpos vivos pueden ser estudiados como el sistema solar, matemáticamente, ésta es una cierta metafísica desarrollada tras los descubrimientos de Galileo, pero que verdaderamente es la metafísica natural del espíritu humano». Vid. H. BERGSON, «L'évolution créatrice», en Euvres, 5. ${ }^{a}$ ed., Paris, PUF, 1991, p. 511. Frey aludía a la génesis posible de este hecho y explicaba que algunos conceptos constituyen una parte integral de la metafísica científica porque representan el resultado final de la evolución del pensamiento humano del pasado. Vid. G. FREY, La matematización de nuestro universo, traducción de J. Barrio, Madrid, Gregorio del Toro, 1972, p. 72.

${ }^{4}$ Vid. W. Heisenberg, Física y filosofía, traducción de F. Tezanos, Buenos Aires, La Isla, 1959 , p. 39.
} 
tica como una excepción a lo normal y razonable. Este hecho se produce igualmente en el estudio del Derecho: es necesario partir desde las reglas generales, y desde ellas los momentos hermenéuticos son vistos como aplicaciones, a veces excepcionales, de esas reglas primeras. Tenemos así una explicación primera sobre el valor de las teorías que quieren explicar todo el objeto de su estudio desde un solo punto de vista: por motivos que habría de explicar la psicosociología, hay que entender que algunos modelos de la filosofía práctica han triunfado en el mercado académico porque se ajustan especialmente bien a la estructura de la razón. Pero puede que la misma estructura racional actual esté severamente condicionada por los modos de pensar dominantes en cada momento de acuerdo con los condicionantes culturales heredados.

Lo cierto es que el espíritu de la cientificidad mecánica nos ha legado la mentalidad que afirma paradigmas científicos que, por omnicomprensivos, han de ser únicos, ya que afirman un solo objeto y un único modo de estudio de ese objeto que asume ocasionalmente caras distintas. Pero estos modelos del pensamiento se han cobrado un precio caro, porque han situado conjuntos racionales que han de portar en sí su propia vida. Estos paradigmas han de ser aceptados por los oyentes o por los lectores porque parten desde algún dato tomado de la experiencia y lo desarrollan coherentemente: basta atender a la abundante literatura que produjeron los filósofos analíticos del siglo pasado para comprobar, con cierto horror, la importancia que concedieron a la coherencia como la garantía de la posibilidad de la intersubjetividad: la lectura del epílogo del tratado de la ciencia jurídica de Bobbio evita dar más explicaciones.

En realidad, estos marcos metódicos parecen estar compuestos por signos o símbolos. Un símbolo es el contenido de alguna representación sensible que ha sido elevada al rango de servidor de un entendimiento puro. La primera consecuencia que produce este mos mechanicus aplicado al psiquismo en general es que las leyes del pensamiento quedan dependiendo de las imágenes mecánicas más elementales: si le hubiéramos preguntado a un jurista del Derecho común si este Derecho vivía al lado del Derecho dictado por el rey, o si estaba por encima o por debajo del Derecho real, seguramente se hubiera quedado sorprendido ante esta forma de expresarse. En cambio, nosotros hicimos nuestras las imágenes físicas más básicas, de lo que resultó no sólo que nos figuramos la existencia de una razón pura, sino que además creemos trabajar al filo de símbolos o imágenes que, gracias a su evidencia y universalidad - pues valen para todos los saberes- garantizan la seriedad de lo que estudiamos o desarrollamos razo- 
nadamente. Hemos perdido el pudor argumentativo y hablamos según los esquemas de sujeto-verbo-predicado, de base-sustentado, de la igualdad, de causa-efecto, de antes-ahora-después, y de muchos más tropos que nos vienen sugeridos ante todo por los movimientos y figuras de los cuerpos físicos. Incluso la negación de las virtualidades de la física moderna ha de ser tomada con cautela: Heidegger reprochaba a Franz von Weizsäcker que este físico (uno de los padres de la mecánica cuántica) fuera impartiendo conferencias sobre el impacto de esta mecánica sobre la filosofía de la ciencia de Kant, porque Weizsäcker, al negar la determinación universal propia de las explicaciones de Newton, estaba juzgando a la libertad humana desde el ángulo de la «libertad» física ${ }^{5}$.

El trabajo del científico, incluso en su vertiente más propiamente pragmática - la que entiende que «The end of knowledge is power»- ${ }^{6}$, ha de ser valorado teóricamente. Pero es esta dimensión más creativa la que levanta las orejas del perro guardián de la ciencia, porque este pequeño cancerbero sabe que hay cosas que no se dejan explicar a costa de disminuir los grados del ángulo desde el que el científico examina sus objetos. Todo producto ya preparado está limitado por las manipulaciones gracias a las que ha sido logrado. Si abordamos las limitaciones metódicas que se basaron en su día en las restricciones de la física clásica, hemos de afirmar que las exclusiones y acotaciones que impusieron aquellos físicos para disponer de un corpus certum para trabajar deben permanecer en el ámbito estricto de aquella mecánica que, por otra parte, ya se ha mostrado — en tanto que explicación simplemente mecánica- extraordinariamente insuficiente.

Penetremos en nuestro terreno e interroguemos a Habermas o Rawls sobre los títulos - es decir, sobre estas experiencias anteriores a la reflexión-que exhiben para reclamar la atención.

\section{LA BRUJERÍA Y LA CIENCIA MODERNA}

El brujo pronuncia unas palabras mágicas, hace unos gestos con las manos, y aparecen los resultados. Fue Goethe quien comparó la naturaleza

5 Vid. C. F. Von WeIzsäcker, «Die Physik der Gegenwart und das physikalische Weltbild», en Die Naturwissenschaften, Heidelberg-Berlin, Springer, 1941, pp. 185-194, citado por M. Heidegger, Conceptos fundamentales. Curso del semestre de verano (Friburgo, 1941), traducción de M. E. Vázquez, Madrid, Alianza Editorial, 1984, pp. 93 y ss.

6 Así, T. HobBes, Elements of Philosophy, en The English Works of Thomas Hobbes, London, John Bohn, 1839, p. 7. 
de la ciencia moderna con el arte de la brujería, ya que el científico se encierra en su laboratorio, establece las leyes de sus actuaciones, combina sustancias cuidadosamente elegidas, las manipula según sus reglas y logra el fiat! final. Pero esto sólo es así con los brujos mayores y serios, porque el aprendiz de brujo no domina este arte y puede llegar a consecuencias no deseables: Walt Disney nos recordó convincentemente esta posibilidad.

Ellos fueron desde el punto a la línea, de ésta a la figura, desde la figura a la extensión. Fue Christian Wolff quien mejor expuso este proceder: en su tratado sobre el Menschliches Thun und Lassen reconocemos los pasos de este mos geometricus de forma prácticamente tangible ${ }^{7}$. Podemos hablar de mos geometricus para referirnos a la filosofía práctica porque los geómetras definen a una figura por una sola de sus propiedades, y normalmente suelen alegar que por la propiedad más sencilla; pero ésta es una argumentación demasiado imprecisa. La respuesta más aproximada sería la siguiente: la propiedad elegida es aquella que suministra un procedimiento de construcción ${ }^{8}$. Porque en este contexto construir es sinónimo de configurar, como cuando describimos aparentemente una circunferencia por la igualdad de los radios. Los moderni eligieron aquella propiedad humana que de la manera más directa e inmediata se refería a la forma constructiva de la sociedad. Así, la razón se sometía a ella misma, a las leyes que se entendían entonces como científicas, porque la geometría era considerada el initium y el fundamentum de toda ciencia, y la razón aplicada a la sociedad se construía a sí misma según una de sus propiedades. No servía el talante de Descartes, cuyo método era aún demasiado dependiente de intuiciones en la razón según sus contenidos innatos. Pero la mixtura de Descartes, de Galileo y de la mentalidad geométrica produjo un nuevo saber de naturaleza imprecisa pero que era evidente para el sentido común moderno: prácticamente nada escapa, al menos retóricamente, al poder avasallador de la geometría, también en las cuestiones del hombre. Bobbio, quizá en mayor medida que Kelsen, expuso sus consideraciones apoyándose sobre los rodrigones de trazos geométricos ya vividos: no hay autor positivista bien conocido que haya ofrecido una teoría más clara, sencilla y «evidente» sobre las normas jurídicas.

7 Pero este constructivismo geométrico no fue creación moderna, estuvo presente en las obras de bastantes filósofos de la Antigüedad y de la Baja Edad Media. Hobbes fue el primero, en el segundo milenio, en ser lo suficientemente desvergonzado para elevar a un plano único lo que hasta entonces no había sido sino un momento del conocimiento.

${ }^{8}$ Vid. R. SAumells, La geometría euclídea como teoría del conocimiento, Madrid, Rialp, 1970, p. 62. 
La verdadera cuestión subyacente sería: ¿cómo llegó a formarse generalizadamente este nuevo sentido común que hacía posibles tantas cosas al mismo tiempo que descalificaba a otras con toda rotundidad? Para resolver esta cuestión, el Iluminismo entendió que bastaba situar al ser humano en el contexto que le correspondía en el Todo Universal, el Trabant. La ciencia sobre el hombre que inauguran Locke, Thomasius, d'Holbach, etc., es ante todo intuitiva, ya que la intuición más en su base es la de dejar que el espíritu9 se abandone a la plenitud de los hechos y se regule incesantemente por ellos, porque el hombre no es más que un sector del todo universal. No hay dualidad entre sujeto cognoscente y objeto conocido: ambos son la misma realidad, aunque el Esprit humano permita una cierta apariencia de autoconciencia. En estas mentalidades, las ciencias jurídicas y políticas descansan en la identidad entre sujeto y objeto, en la identificación entre razón teórica y razón práctica, y es precisamente esta recíproca implicación idéntica la que permite, como connaturalmente, que el sujeto llegue a su plenitud en su adecuación a lo que es y hay. Era un círculo mágico porque no estudiaba ni describía: la conciencia de la identidad de toda la realidad con ella misma actuaba continuadamente como contexto de justificación, y como componía la misma realidad que lo expuesto o justificado, lo uno se explicaba y garantizaba por lo otro ${ }^{10}$.

Se trataba en realidad de una presentación mítica, pues el mito se justifica por lo que presenta: lo que se ve en el mito, se explica en él. Es un proceso similar al de la geometría: el círculo se forma por el giro de un radio, y no hay interrogante anterior ni ulterior sobre esta construcción y su validez ${ }^{11}$. Estas imágenes avanzadas argumentativamente y preñadas de contenidos eran válidas porque la vista se explica por la imagen que proporciona la misma vista. Los filósofos empiristas comprendieron pronto las virtualidades que les prestaba este estilo visual de considerar el conocimiento humano, y Hobbes declaró la naturaleza de pictures de las imágenes que posee-

${ }^{9}$ El espíritu solamente puede ser entendido en el sentido que lo hace C.-A. Helvetius en De l'Esprit, esto es, como conciencia de la necesidad.

${ }^{10}$ Hobbes, que reducía la filosofía a geometría, como manifiesta de forma especialmente clara en sus Elements of Philosophy, indicaba que la geometría no es distinta de la geometría misma. Vid., entre otros lugares de esta obra, p. 89.

${ }^{11} \mathrm{La}$ conciencia medieval y moderna percibió esta analiticidad, y captó pronto que las figuras geométricas no se prestaban a explicaciones matemáticas, y de ahí las denuncias de Alejandro De Alés ya en el siglo XIII y de ahí también la desconfianza de Descartes frente a los datos proporcionados por los sentidos; todas las denuncias que hace en su Discurso del Método se refieren a las falacias a que llevan las explicaciones racionales de los constructos geométricos. Es obvio que desconfiaba ante todo de los datos proporcionados por la vista. 
$\operatorname{mos}^{12}$. En esta misma línea, desde la irrupción de la filosofía lingüística a comienzos del siglo Xx, estas consideraciones han sido reforzadas por las doctrinas semióticas, que mantienen que el conocimiento humano consiste en un flujo continuo de comunicación, y que la comunicación consiste en vivir en un mundo en el que los signos o símbolos «valen» igualmente para todos. Ferdinand de Saussure recogió ideas dispersas a comienzos del siglo xx y algo más tarde Noam Chomsky popularizó esta forma de entender la comunicación humana. Sucedió que así como los fenomenistas anteriores habían ido desde el concepto a la palabra, en esta segunda reducción (lingüística) el proceso cognoscitivo procedió desde la palabra al signo, o, por decirlo con más precisión, estudió el lenguaje formal, que estaría rigurosamente separado del habla ${ }^{13}$. El «nominalismo» de hoy es fundamentalmente simbólico ${ }^{14}$, ya que proviene de las diferencias entre las palabras usadas sin necesidad de referencia al ámbito extralingüistico. Esto conlleva una gran economía de esfuerzos para algunos filósofos actuales, que ya no se ven forzados a matizar sus explicaciones según doctrinas epistemológicas, sino que parten directamente y sin más explicaciones desde los signos o símbolos en que consiste, según ellos, toda comunicación. Los que integran las filosofías sistémicas proceden de este modo, y los que mantienen filosofías hermenéuticas fuertes hacen lo mismo ${ }^{15}$. Para

12 Vid. T. HobBes, Elements of Philosophy, op. cit., p. 84.

13 Ésta es la tesis que recorre el Curso de De Saussure.

${ }^{14}$ Saussure indica que: «Mientras que el lenguaje es heterogéneo, la lengua así delimitada es de naturaleza homogénea: es un sistema de signos en el que sólo es esencial la unión del sentido y de la imagen acústica, y en el que las dos partes del signo son igualmente psíquicas». Vid. F. De SAussure, Curso de lingüística general, traducción de M. Armiño, 3. ${ }^{a}$ reimp., Madrid, Akal, p. 41. Más adelante es bastante más explícito: «Todas las demás instituciones humanas [...] están fundadas, en diverso grado, en las relaciones naturales de las cosas [...] La lengua, por el contrario, no está limitada en nada en la elección de sus medios, porque no vemos qué podría impedir asociar una idea cualquiera con una secuencia cualquiera de sonidos. Para que se comprendiera bien que la lengua es una institución pura, Whitney insistió, con toda razón, en el carácter arbitrario de los signos, y con ello situó a la lingüística en su verdadero eje» (pp. 114-115).

${ }_{15}$ Habermas explica que las filosofías de la conciencia abandonan ya el horizonte usual con su modelo de conocimiento basado en la percepción y representación de objetos. En lugar del sujeto aislado, que se orienta hacia los objetos y se convierte él mismo en objeto en el proceso de reflexión, no solamente aparece la idea de un conocimiento mediado lingüísticamente y referido a la acción, sino también el nexo entre la praxis y la comunicación cotidianas, en la que se inscriben las realizaciones cognitivas que en su origen son intersubjetivas al tiempo que cooperativas. Que este nexo se estudie como forma vital o como mundo vital, como praxis o interacción mediada lingüísticamente, como juego de habla o conversación, como trasfondo cultural, tradición o historia de influencia, es un hecho que resulta indiferente. Vid. J. Habermas, Conciencia moral y acción comunicativa, traducción de R. García Cotarelo, Barcelona, Península, 1985, p. 19. La fundamentación de este rechazo de 
ellos es suficiente con destacar un horizonte cultural o lingüístico común que se expresa o consiste en signos; la redención humana ya no dependerá de las «cosas» expresadas en las palabras, sino de la carga de sentido que porta nuestra tradición heredada (Heidegger, Gadamer), o de la carga de sentido que está encastrada en nuestro estilo de vida, caracterizado ante todo por la exigencia de la igualdad individual. Este último es el caso de Habermas y, en menor medida, también de Rawls. No tienen en cuenta la observación de Hobbes: que la igualdad no trasciende la cantidad, por lo que la forma de predicación que usemos al tratar de los cuerpos no trascenderá las formas de predicación que son propias del discurso sobre la cantidad ${ }^{16}$. Nuestro pensamiento simbólico es hoy mítico.

El primer gran paso ya estaba dado al reducir las cosas a los contenidos de los símbolos o pictures, porque así como todos los símbolos se mueven en el mismo plano de la vida humana, las cosas transmitidas por ellos son igualmente amorfas o uniformes; acabaron de hacer realidad el sueño moderno de presentar a nuestro mundo como una gran superficie sin relieves: poseían ya, analíticamente, un objeto unitario que estudiar ${ }^{17}$. Los teóricos del Derecho procedieron de este modo, ya que adoptaron una forma de trabajar que, por sus propios términos, exigía una única clase de argumentos. Estos argumentos se desarrollaron siempre según el estilo de la nueva mecánica. Sabemos que la mecánica investiga el tipo aparentemente más elemental del movimiento, el que se realiza mediante impulsiones que originan desplazamientos locales: Hobbes fue muy explícito cuando

las filosofías de la conciencia posee un carácter singular con su propuesta de una vuelta al «sentido común»: «Lo decisivo es que todos estos conceptos de sentido común alcanzan un rango que hasta ahora estaba reservado a los conceptos fundamentales de la epistemología, sin que por lo demás tengan que funcionar como éstos. Las dimensiones de la acción y del habla no tienen por qué anteponerse a la cognición» (ibid.).

${ }_{16}$ Vid. T. HobBes, Elements of Philosophy, op. cit., pp. 20-26. A pesar de esta exigencia, los teóricos de la justicia actuales hablan de la coherencia personal, de tener agallas, de decencia o de noúmenos. Debieran haber hablado de estas «realidades» como hizo Hobbes al tratar del alma, que según él es un «thin, fluid, transparent body». Vid. T. HoBBEs, De corpore politico, en The English Works of Thomas Hobbes, London, John Bohn, 1839, p. 309.

${ }^{17}$ Los iluministas tendieron a considerar que la razón habita o se desarrolla en un «espacio lógico», de modo que los contenidos mentales del tipo que fueran habían de ser elevados a la condición de servidores de un entendimiento puro que revistiera alguna forma propiamente geométrica. Kant muestra esta vinculación íntima entre espacio y razón cuando escribe que: «Nuestra razón no es una especie de llanura de extensión indefinida y de límites conocidos sólo de un modo general, sino que más bien ha de ser comparada con una esfera cuyo radio pueda encontrarse partiendo de la curvatura de su superficie [...] desde ahí podemos igualmente señalar con seguridad el volumen y los límites de la esfera». Vid. I. KANT, Crítica de la razón pura, traducción de P. Ribas, Madrid, Alfaguara, 1988, A 762. 
explicó todo movimiento como el cambio de un lugar a otro lugar ${ }^{18}$. Estas teorías sólo podían considerar desplazamientos lógicos (¿cómo llamarlos?) según el esquema del antes-después. Entendieron que el motor propiamente humano era la voluntad, que ponía algo nuevo en el mundo.

El gran instrumento unificador era la noción de causalidad usada universalmente: los modernos sólo tienen en cuenta la causalidad eficiente - una secuela de su imagen mecanicista del mundo- que contempla a unas causas que siempre operan desplazando «lógicamente», esto es, de atrás a adelante, por impulsiones guiadas por el principio de la ubicuidad o no-contradicción ${ }^{19}$. Le es ajena la causalidad final, y si establecen teleologías (más que de teleologías hay que hablar de simples estrategias teleológicas), se trata de constructos sintéticos a priori, cuyo núcleo más interno está constituido por la simple causalidad mecánica. Ahora es indiferente que los de Uppsala entendieran este poner en el mundo de una forma, y Kelsen, Bobbio o Hart de otra: ambos grupos coinciden en la mentalidad de fondo, no superada en modo alguno por Dworkin, ni, desde otras bases, por los sistémicos. Para ellos, la razón era pasiva, y la voluntad, siempre activa, debía ser guiada por una imposible razón práctica, llamada Filosofía del Derecho en nuestra disciplina. La intuición figurativa más general estaba clara en el plano imaginativo (llamado por algunos geómetras actuales la conciencia objetiva ${ }^{20}$ y desde ahí compuso la nueva teoría: sólo faltaba trasladarla al terreno de las ciencias humanas ${ }^{21}$.

18 Vid. T. HobBes, Elements of Philosophy, op. cit., p. 109.

19 Sobre la relevancia del principio de acción-reacción vid. ibid., p. 391.

${ }^{20}$ Descartes prefiere la palabra «imagination». Vid. R. DESCARTES, «Seconde méditation», en Euvres et lettres, Paris, Gallimard, 1953, p. 280. Saumells define a la conciencia objetiva como: «El ámbito de una cierta forma de presencia propia de los objetos en tanto que están destinados a su conocimiento». Vid. R. SAumells, La geometría euclídea..., op. cit., p. 34.

${ }^{21}$ Fue J. G. Bluntschli en su Allgemeine Staatslehre, uno de los manuales de Derecho del Estado (Staatsrecht, una expresión difícilmente traducible para nosotros) más conocido en el siglo XIX, quien hizo operativas estas ideas en la reconstitución poiética de la convivencia política. El Staatsrecht tuvo problemas de pureza metódica, aun en las manos de Moser y Pütter, ya que dependía excesivamente de la Ciencia Política (Kameralwissenschaft) más general. Bluntschli comenzó esta obra distinguiendo cinco saberes distintos: la Historia de la Nación, la Estadística, la Economía nacional o política, la Doctrina sobre la sociedad (Lebre der Gesellschaft) y el Staatsrecht. Las cuatro primeras son ciencias auxiliares del Staatsrecht, pues éste no es ni una ni otras, ni el conjunto de ellas, sino él es el Estado: «Der Staat, wie er ist, in seinen geordneten Verbältnissen, das ist das Staatsrecht». El Derecho se comporta sobre la política como el orden sobre la libertad, ya que el Staatsrecht examina la juridicidad de las situaciones y la política se ocupa de la corrección (Zweckmässigkeit) de esas mismas situaciones. Ambos saberes, el derecho y la política, consideran el Estado indiscriminadamente (im grossen und ganzen), pero cada una de estas consideracio- 
Esta última empresa no les planteaba dificultades: es propio del pensamiento simplista ver la vida como la aplicación de una regla a un estado de cosas a la vez claro y determinado. Ellos disponían de una regla universal, o creían disponer de ella, porque el plano de la objetividad inconscientemente asumido presiona a las conciencias con tal fuerza que no son conscientes de haber elegido ellos su propia objetividad, esto es, sus propias reglas, ni de estar justificándose a sí mismas al mismo tiempo que presentan su objeto construido de acuerdo con ellas. Una vez que la ciencia ha quedado identificada con el objeto que considera, es el propio objeto el que queda diluido en la ciencia, y ahora todo el tema consiste en encontrar las reglas que dirijan la constitución de la ciencia, es decir, de todo el conocimiento.

No fueron conscientes de estar usando indistintamente el criterio compuesto por la distinción entre el contexto de presentación y el contexto de justificación, y la falta de matizaciones les llevó a perder de vista las diferencias diversas por cambiantes entre ambos contextos ${ }^{22}$. El contexto de presentación sería el discurso expuesto según los condicionantes de la cultura

nes científicas lo estudia desde unos puntos de vista y direcciones distintas. El derecho que constituye el Estado y el Estado constituido por él son una misma realidad: tenemos así una ciencia que no se distingue de su objeto, al que crea al mismo tiempo que lo considera, de forma que no existe diferencia entre el criterio puro ordenador y aquello que es creado mediante la ordenación. No es que Bluntschli propusiera separar Staatsrecht y Politik: «No es lícito separar el Derecho del Estado y la Política. El Estado real vive, esto es, es la unión de Derecho y política». No parece que Gaspar Bluntschli fuera original: Feuerbach y Kielruff en Alemania, y Austin y Holland en Inglaterra habían dejado claro que lo que puede ser correcto desde el punto de vista específicamente jurídico puede ser incorrecto desde otros puntos de vista. Pero Bluntschli se atrevió a preparar en mayor medida a las mentes — entre otras cosas gracias a la enorme difusión de su obra - para esta consideración autónoma del mundo legal, de forma que de ahora en adelante ya no era sino cuestión de tiempo que alguien identificara expresamente y con más pretensiones de exclusividad del Estado con las mismas leyes dictadas por él. He utilizado la sexta edición de la obra de Bluntschli (Stuttgart, 1886). Entonces ya había sido publicado en Francia y traducido por A. De Riedmatten bajo el título de Le Droit Public Général, y tuvo dos ediciones, en 1880 y 1885. También estaba publicado en Italia como Dottrina Generale dello Stato Moderno, en versión de $G$. Trono.

${ }^{22}$ Gabriel Biel, en la segunda mitad del siglo xv, distinguía limpiamente ambos contextos: «Tertium notandum: quod est duplex actus intellectus, aprehensivus et judicativus. Primus est respectu cuiuscumque potentiae terminare actus potentiae cognitivae, sive sit complexum, vel incomplexum. Sic aprehendimus terminos propositionis, et ipsas propositiones, argumenta et syllogismos, demonstrationes: et universaliter omnia, quae respiciunt objective a potentia intellectiva. Actus judicativus est actus intellectus, quod assentit, vel dissentit propositioni verae, vel falsae: et illa est tantum respectu complexi propositionalis [...] intellectus babet duos actus scil. aprehensivum et judicativum. Et sunt separabilis, primus a secundo». Vid. G. BIEL, «Prologus, Quaestio Prima», Commentarii doctissimi in IV Sententiarum libros, Brixiae, 1574. Domingo De Soto, desde una posición filosófica general distinta, también distinguía ambos momentos y escribía: «Unde cum duae sint partes scientiae, ut rem intelligas, altera ut 
(geométrica, matemática, física, ética, etc.) en la que cada época expone sus aportaciones ${ }^{23}$. El contexto de justificación estaría compuesto por los presupuestos y las operaciones racionales por las que los científicos filtran los datos suministrados por los sentidos para declarar a estos datos como válidos científicamente. Éste era el momento más altamente dogmático o miedoso $^{24}$-las teorías modernas estaban consumidas por el miedo ${ }^{25}$ y por ello obsesionadas por el rigor- porque ellas negaban las capacidades de los sentidos y de la mente humana para sustituirlas por reglas validadoras de la experiencia que no tanto afirmaban como negaban, porque estos métodos se definían más bien por sus restricciones.

Ya que aludo a eliminaciones objetuales, veamos la primera de todas ellas: la posibilidad de la validez de estas reglas se fundamentaba ante todo en una representación de los objetos uniformes o amorfos; en un segundo momento menos intuitivo, prolongaban estas tesis primeras (ahora convertidas en axiomas) según argumentos de lógica o conveniencia; los empiristas han sido siempre muy razonadores o racionalistas. Entendieron que la primera condición para que los contenidos del conocimiento fueran uniformes era negar algún tipo de sustantividad en ellos, y Hobbes estableció que no hay diferencias entre las sustancias y los accidentes ${ }^{26}$. Históricamente la visión geométrica de las posibilidades y alcance del conocimiento se mostró en la lucha por la negación de las «sustancias», a las que concebían como el soporte «material» de los fenómenos, unos soportes que habían de estar ubicados en las coordenadas formadas por la representación usual enton-

credas». Vid. D. DE Soto, «Quaestio Prima super Prologum Porphyrii», In Dialecticam Aristotelis Commentarii, Salamanca, 1580, p. 13.

23 Éste ha sido un tema recurrente en la historia de la filosofía. El mismo Descartes lo expresaba con precisión: «Car l'action de la pensée par laquelle on croit une chose, étant celle par laquelle on connait qu'on le croit, elles sont souvent l'une sans l'autre». Vid. R. DESCARTES, Discours de la méthode, op. cit., 3. ${ }^{a}$ parte, p. 141.

${ }^{24}$ Lord Shaftesbury ya indicaba perspicazmente que las actitudes dogmáticas surgen desde el miedo. Vid. A. A. COOPER (conde de Shaftesbury), «The Moralist: A philosophical Rhapsody», en Characteristics of Men, Manners, Opinions, Times, vol. II, Hildesheim-New York, Olms, 1978 (1711), p. 187.

${ }^{25}$ Hegel escribía que: «Las experiencias, los experimentos, las observaciones, no saben lo que en realidad hacen, no saben que el único interés que se toman por las cosas es precisamente la certeza inconsciente interior de la razón de encontrarse en la realidad misma». Vid. G. W. F. HegeL, Lecciones sobre la historia de la filosofía, traducción de W. Roces, vol. III, México, FCE, 1985, p. 223. Efectivamente, la razón de cada individuo quiere para sí la (relativa) seguridad del objeto que conoce porque en el conocimiento se produce ese estado personal que describía Heidegger: «En el ámbito más próximo de lo ente nos creemos en casa. Lo ente es familiar, seguro, inspira confianza». Vid. M. HEIDEGGER, «La época de la imagen del mundo», en Caminos del bosque, traducción de H. Cortés y A. Leyte, Madrid, Alianza, 1997, p. 46.

26 Vid. T. HobBes, Elements of Philosophy, op. cit., p. 104, entre otros lugares. 
ces de espacio-tiempo ${ }^{27}$. Locke fue muy explícito al proponer el mito hindú de la tortuga que soporta el mundo para mostrar el absurdo de la defensa de las sustancias ${ }^{28}$. El asunto empeoraba porque estos empiristas entendían que los filósofos que habían afirmado las sustancias mantenían que, mediante una intuición especialmente directa, los hombres conoceríamos lo que son las cosas en sí. Ignoraban que Tomás de Aquino había establecido que los hombres no podemos conocer lo que son las cosas en sí mismas, sino que estas cosas se nos manifiestan por los efectos de sus operaciones o movimientos ${ }^{29}$; ignoraban también que el de Aquino explicó que la naturaleza no venía constituida por las formas o esencias inmutables, sino que la naturaleza de cada cosa era esa fuerza que hace que cada existente tienda hacia su realización «con toda la fuerza de su ser» ${ }^{30}$.

Una observación incidental: he citado a Tomás de Aquino como si fuera tout court autor que poseyera una autoridad similar a la de Einstein o Heisenberg. Es patente que el de Aquino no poseía los conocimientos físicos de estos autores mencionados, y parecería que sus observaciones han de ser dejadas hoy de lado. Pero el problema que se discute aquí se mueve en un plano distinto del científico en sentido estricto. Sucede que la ciencia moderna ha vivido en dos niveles hasta cierto punto paralelos: uno, el de las comprobaciones verificables que son inervadas en leyes generales; el otro plano puede ser llamado «ideal» a falta de otro término más preciso; pues la mecánica clásica suponía un todo universal ordenado según la ley eterna del movimiento, que consistía en impulsiones concretas. El marxismo poseyó mucha de esta carga «ideal», y supuso igualmente demasiadas cosas. Hoy, los autores sistémicos se dejan guiar por intuiciones personales que tampoco son verificables en modo alguno; pues si Maturana entiende

27 Según Hobbes, una sustancia es una «cosa» que subsiste por sí misma y que ocupa un lugar en el espacio. Vid., por ejemplo, T. HobBEs, Elements of Philosophy, op. cit., p. 102.

28 Aludía al mito indio que mantenía que la tierra es sostenida por los hombros de un gigante y que el gigante se apoya sobre una tortuga. ¿Sobre qué se apoya la tortuga? Vid. J. Locke, «Essay of Human Understanding», The Works of John Locke, London, 1823, p. 167.

29 La literatura de DE AQuino sobre este tema es extensa. Sobre el conocimiento de las cosas sólo por sus efectos vid., por ejemplo, T. DE AQuino, In tres libros de Anima, vol. III, L. II, $\mathbb{S} 13$, Antwerpiae, 1612. Mantiene que sólo conocemos a las cosas por «accidentes» suyos (ibid., L. I, Lectio 1). Su actitud más general puede quedar expresada así: «Nescimus nisi quedam infima rerum». Vid. T. DE AQuINO, Liber de Veritate Catholicae Fidei contra errores infidelium seu «Summa contra Gentiles», Torino-Roma, Marietti, 1961, \2273. Esta tesis, más contextualizadamente, en mi estudio «La "adaequatio hermeneutica” en Tomás de Aquino», Philosopbica, núm. 35, Valparaíso, 2009, pp. 95-120.

30 T. DE AQuino, «Secundum totam essendi potestatem», Liber de Veritate Catholicae Fidei..., op. cit., $\$ 260$. 
que los protomovimientos que han de explicarlo todo son los que observa el investigador en citología, esta tesis únicamente responde a una intuición muy personal. Las digresiones propiamente filosóficas que se desprenden desde las fórmulas de Einstein, o desde la fe en la máquina universal, o desde algunas observaciones tomadas de sectores concretos de la biología, que aún hoy circulan entre nosotros bajo la veste de lo propiamente académico, componen solamente generalizaciones que ha de pagarlas cada investigador a su propia costa. Estas generalizaciones son tan radicales que sobrepasan completamente el ámbito tanto de las ciencias inductivas como de las deductivas, y sólo podemos decir que han nacido desde las profundidades de la capacidad humana para intuir. Heisenberg vivió dos momentos en su vida profesional: el primero, más dependiente de las tesis básicas de la física clásica; el segundo, plenamente aristotélico en las bases últimas, una vez que el espíritu que parece desprenderse desde la mecánica cuántica le llevó hacia el prototipo metódico de la biología. En los temas últimos, exceptuados algunos errores groseros, tan válidas son las intuiciones de un filósofo de la Antigüedad como de la Edad Media o del siglo xx.

Pero volvamos al tema principal. Estos constructos que nos ha legado la historia reciente y que hoy gozan de una segunda vida parten desde un solo principio y desarrollan una argumentación que quiere ser unitaria porque exponen unos teoremas que avanzan en una sola dirección; podemos llamar a estos sistemas éticas de dirección única o éticas de línea recta ${ }^{31}$. Para llegar este resultado no sólo los axiomas iniciales han de estar fijados excluyentemente, sino que los razonamientos — ¿matemáticos o geométricos? - han de poseer la misma índole. Pero este empeño desconcierta al investigador, que contempla que la justicia requiere tratar igual a los iguales y desigualmente a los desiguales: porque no tiene sentido exigir al profesor, en cuanto profesor de Teoría del Derecho, que juegue bien al tenis.

\section{LA UNIDAD LÓGICA PUESTA POR EL MÉTODO}

Funcionaron con lo que podríamos llamar el raciocinio-función, porque tomaron un dato de la vida real y, mediante razonamientos lógicos

31 Así lo indicaba Bertalanffy: «La simple "reducción" de las partículas elementales y las leyes ordinarias de la física no parece ser factible. En comparación con el proceder analítico de la física clásica, con la resolución en elementos componentes y causalidad lineal o unidireccional como categoría básica...». Vid. L. V. BERTALANFFY, Teoría general de los sistemas. Fundamentos, desarrollos, aplicaciones, traducción de J. Almela, México, FCE, 1989, p. XVI. 
extraídos desde sus contextos, lo pusieron al servicio de la función teoremática de una realidad más amplia, ya imaginada normalmente antes de emprender la investigación, y normativa de hecho en ese estudio. No hay distinción entre los conceptos afirmados inicialmente y las posibilidades lógicas y operativas que van adjuntas a ellos. Un espíritu algo cándido estaría tentado a entender que el análisis de los datos de la realidad estudiada y la síntesis posterior de estos datos conducen naturalmente al concepto del derecho; pero ni aquel dato primero es inocente, ni los razonamientos lógicos posteriores son tampoco inocuos, de forma que pudieran servir para investigar qué es el derecho, qué son los derechos humanos, o que es el derecho subjetivo. Porque la función predeterminada se erigió en la guía de la investigación, y lo que más destaca en sus obras es la unidad subyacente que confiere - desde aquella función teórica aparentemente inicial - unidad, armonía y pureza al sistema: así creyeron estar construyendo un edificio científico, y desde entonces la pretensión sistemática se ha erigido en sinónimo de cientificidad o seriedad de las investigaciones. Quisieron mirar más allá del sentido de cada cosa para comprenderlo en términos de su génesis y finalidad necesaria y única ${ }^{32}$. Entendieron que así construirían una ciencia que sobrepasara los elementos ofrecidos por la simple experiencia. Hobbes (tan malentendido usualmente) buscó este guión conductor en el deseo de justicia y seguridad; Locke, en el aseguramiento de las libertades sobre las propiedades privadas; Kant buscó un sujeto libre, en su persona y en sus propiedades, y nos propuso la figura de la juristische Person.

En este punto, como en tantos otros, no hubo diferencias entre los fenomenistas como Locke o los idealistas como Fichte, pues ambos se nutrían de este mismo ambiente intelectual. La totalidad fue anticipada en ambos casos, y mientras que los idealistas hicieron de esta exigencia el punto decisivo de sus explicaciones, viendo la conciencia o el yo como una progresión o regresión hacia sí, los materialistas se limitaron a sentar

32 Desde Hobbes las ciencias han dejado de ser descriptivas, porque al establecer las condiciones para la aceptación de los datos iniciales desde los que ha de arrancar el razonamiento, ya introducen síntesis a priori en los datos que componen la estructura de tal momento genético. Esta forma de proceder ha existido siempre y presumiblemente seguirá siempre operativa.

Pero el momento que diferencia a esta ciencia reside en la voluntaria autolimitación de las posibilidades cognoscitivas. Todos argumentamos para alcanzar un fin, y la institución más conocida que ha instituido la sociedad a este efecto es la de la abogacía. Pero los abogados que rozan los límites de la honestidad tratando (mediante zorrerías de juzgado) de declarar inválidas las pruebas, no es el prototipo de este profesional. 
tesis contradictorias mientras explicaban la progresión y amplificación de las sensaciones desde los datos protocolares hacia totalidades más amplias de tipo intelectual a las que, sin embargo, presentaron como propiamente necesarias o universales ${ }^{33}$. El estatuto de la construcción quedó identificado con el estatuto de lo construido: en realidad es este último el que domina todas sus construcciones, aunque momentáneamente se desgrane de forma instrumental en procesos metódicos intermedios. Una vez introducida la totalidad mediante las restricciones oportunas, es ella la que domina en su unidad, pues el espíritu moderno no es capaz de concebir totalidades que no sean unitarias, y entonces se produce la tensión típica de esta totalidad que aspira a volver a reintroducir en sí a los elementos aparentemente dispersos por las determinaciones, unos elementos que, por lo demás, permanecen inexplicables para ellos. Pero esto no preocupa porque para la mirada crítica del filósofo moderno y contemporáneo todas las realidades son diferentes sólo en apariencia, y han de concebir la perfección o la corrección como un volver a traer a casa al hijo descarriado. En este punto, los únicos coherentes fueron los idealistas, que siguieron la tesis del primado kantiano de la filosofía práctica, y, en un modo más débil, los materialistas francófonos y anglosajones de primera hora. Locke, apasionado en su aparente frialdad, incurrió en contradicciones porque afirmó elementos normativos — los derechos innatos - allí donde solamente debería existir una simple descripción de fenómenos.

Tenemos unos primeros elementos para el juicio: estos constructos consistirían en tomar un número de conceptos fundamentales proporcionados por la misma observación — pues el empirismo se autopresentó como la explicación científica que no debe a nada a nadie- para derivar desde

${ }_{33} \mathrm{Al}$ hablar de contradicciones no me refiero tanto a las posibles incoherencias que yo pudiera creer observar en las bases de estas filosofías - pues una explicación sobre el hombre no puede ser descalificada sin más por la denuncia de una contradicción como de tipo lógico en la base de un sistema filosófico- como a las contradicciones concretas y puntuales que cualquiera encuentra en sus explicaciones. Si denunciara simples antinomias lógicas me haría acreedor a los reproches de Fichte cuando escribe: «Mas, ¿qué dice este tan temible principio lógico de contradicción con el cual se pretende derribar por el suelo, de un golpe, nuestro sistema? Hasta donde me es conocido, nada más que esto: si un concepto está ya determinado por una cierta nota, no puede ser determinado por otra opuesta a la primera. Pero por qué nota haya de estar determinado primitivamente un concepto no lo dice ni puede, por su naturaleza, decirlo, pues el principio supone como ya habida la determinación primitiva, y sólo tiene aplicabilidad en tanto se la supone como habida. Sobre la determinación primitiva habrá que ir a buscar noticia en otra ciencia». J. G. FICHTE, Introducción a la teoría de la ciencia, traducción de J. Gaos, Madrid, Sarpe, 1984, segunda introducción, parágrafo 7, pp. 126-127. 
ellos los demás conceptos según un desarrollo teoremático que fue llamado un sistema. Se trata de una construcción en la que los términos introducidos son definidos por términos previamente usados en la argumentación: el uso de los primeros términos justifica la operatividad de los factores posteriores. De este modo, el constructo en las ciencias humanas sería una teoría al margen de la entropía inevitable, ya que tendría doble dirección: podríamos ir desde los axiomas primeros a los desarrollos posteriores, o desde los conceptos implicados en estos desarrollos a los axiomas prime$\operatorname{ros}^{34}$, pues la intimidad del constructo reside en el construir o en el reducir, siempre construyendo gracias a reglas de traducción que proporcionan las funciones proposicionales necesarias, para ir desde aquellos axiomas a estos segundos conceptos, y desde estos conceptos a aquellos axiomas. Es una forma de construcción simplemente fenoménica que no admite la inferencia de entidades en el conocimiento, y que trata de reemplazar las entidades inferidas por construcciones, porque entiende —en última instancia- que inferir entidades es poblar ontológicamente el mundo: en el lugar de las entidades quiere construcciones lógicas que no tienen ninguna entidad ontológica porque serían simples ficciones simbólicamente construidas. De acuerdo con este planteamiento meramente funcionalista, una «entidad» existe o es demostrable (expresiones sinónimas en este contexto) solamente cuando se puede proporcionar una regla o técnica para su construcción.

Suponían una totalidad o conjunto operativo total ${ }^{35}$, y en definitiva una identidad de esta totalidad consigo misma conseguida mediante la representación paralógica de uniformidad e infinitud ${ }^{36}$. Las tesis de Gabriel Vázquez, Luis de Molina y Francisco Suárez relativas a la identidad de cada sustancia consigo misma (aunque la «metafísica» de Suárez daría mucho que hablar y discutir) fueron traspasadas a la idea misma de espa-

34 Ésta es una de las tesis más básicas de Hobbes. Vid., por ejemplo, T. HobBEs, Elements of Philosophy, cit., p. 75.

35 Diderot explicitaba con brevedad digna de agradecimiento lo que otros muchos ilustrados exponían tras muchas páginas: «La independencia absoluta de un solo hecho es incompatible con la idea de totalidad, y sin la idea de totalidad ya no hay filosofía». Vid. D. DiDEROT, Sobre la interpretación de la naturaleza, traducción de J. Mateos, Barcelona, Anthropos, 1992, $\mathbb{X I}$, p. 23.

${ }^{36}$ Los medievales no entendían que el espacio fuera uniforme. Tomás de Aquino establecía una adecuación entre la cosa y el espacio que ésta había de ocupar, de modo que ante todo el locus había de ser adecuado (dignus) a la cosa de que se trataba. Vid. T. DE Aquino, In octo libros Physicorum Aristotelis Expositio, Torino-Roma, Marietti, 1965, $\mathbb{\$} 446$. Por lo demás, él entendía que el espacio tenía naturaleza circular (ibid., $\$ 461$ ). Más adelante, en el $\$ 476$ de esta obra, añade que el espacio tiene muchas dimensiones invicem penetrantes. 
cio como conjunto de extensión uniforme y siempre idéntico a sí mismo en el que están situados los cuerpos: desecharon la tesis medieval que entendía que el espacio tiene dimensiones distintas ${ }^{37}$. Esta metafísica sustancialista moderna decidió el futuro de la geometría y la lógica, y el mos geometricus extendió esta uniformidad también a las ciencias humanas. Samuel Pufendorf — que tanto debía a Suárez- ${ }^{38}$ tuvo fácil este trabajo porque solamente hubo de declararse nominalista, de forma que el mundo de esencias racionales inmutables que afirmaron los jesuitas quedó reduciendo a unos mandatos de Dios a los hombres, ahora conocidos bajo el nombre de entes morales.

Si reitero, vemos que estamos ante anticipaciones en la que los factores aparentemente posteriores forzaban el movimiento «lógico» de los elementos anteriores, y esta anticipación introducía la unidad total, sistemática, que realmente no era tanto un resultado como la regla maes$\operatorname{tra}^{39}$ : la unidad reside en la concordancia; el principio de no-contradicción introduce el sistema in nuce; el conocimiento se identifica con el juicio, que incorpora lo particular al sistema; todo pensamiento que no tienda al sistema carece de dirección o es autoritario por arbitrario ${ }^{40}$. Su seguridad se basaba en que suponían una adecuación cognitiva ya siem-

37 Tomás de Aquino escribía: «Quod locus sit unum de quattuor; scil. vel materia, vel forma, vel aliquod spatium inter extrema continentis; vel si nullum spatium est inter extrema continentis, quod habeat aliquas dimensiones, praeter magnitudinem corporis quod ponitur infra corpus continens, oportebit dicere quartum, scilicet quod habeat aliquas dimensiones». Vid. T. De Aquino, In octo libros Physicorum..., op. cit., $\$ 456$. Poco después, en el $\$ 461$, rechaza la noción de espacio como un continuum indefinido.

38 Según Carl Schmitt, Pufendorf sólo fue el heredero de Suárez. Vid. C. Schmitt, Escritos políticos, traducción de F. J. Conde, Madrid, Doncel, 1975, p. 17. También expuesto en ÍD., El concepto de lo político, traduccion de E. Molina y V. R. Crisafio, Buenos Aires, Folios, 1984, p. 80.

${ }_{39} \mathrm{M}$. Diesselhorst explica esta exigencia en Hobbes: «Diese resolutiv-kompositive Methode wendet Hobbes auch auf die moral- und Gesellschaftsphilosophie an. Dabei sind zunächst zwei Prämissen dieser Methodenübertragung klarzustellen: a) Auch der Mensch ist ein Körper; auch seine Handlungen ergeben sich mechanisch notwendig als Bewegungen, die durch die Bewegungen anderer Köper vermittels der Sinneseindrücke mechanisch notwendig hervorgerufen werden. b) Die Menschen schaffen durch diese (mechanisch) notwendigen Handlungen den Staat und folgeweise die bürgerlichen Gesetze auch. So, wie etwa ein Würfel auf die gleichförmige Bewegung einer Fläche im Raum zurückgeführt werden kann, diese wiederum auf die gleichförmige Bewegung einer Linie und diese schließlich auf die gleichförmige Bewegung eines Punktes, und so wie der Würfel nach dieser Auflösung wieder entsprechend zusammenzusetzen ist, so löst sich der Staat in die ihn mechanisch notwendig ergebenden Vorasussetzungen auf, und so kann man schließlich seine Zusammensetzung apriorisch demonstrieren». Vid. M. DiesselHorst, Ursprünge des modernen Systemdenkens bei Hobbes, StuttgartBerlin-Köln-Mainz, W. Kohlhammer, 1968, p. 10.

40 Vid. M. Horkheimer y T. Adorno, Dialéctica del Iluminismo, traducción de H. A. Murena, Buenos Aires, Editorial Sudamericana, 1987, pp. 102-103. 
pre dada entre sus conceptos y las legalidades que afirmaron. Era previsible este sentimiento personal, ya que los conceptos tenían en sus teorías valor universal porque suponían implícitamente que la materia era única y el movimiento era igualmente único: la identidad de la naturaleza (¿de la materia?) consigo misma garantizaba la universalidad de las formas. Apareció así un marco epistemológico que operaba continuadamente como contexto de justificación, constituido también por el sentimiento de la unidad de todo lo natural en sentido estricto ${ }^{41}$, en su constitución y en su dinámica. Hegel lo indicaba claramente a propósito del materialismo de Locke ${ }^{42}$ : «Allí donde el pensamiento es algo concreto por naturaleza, donde el pensamiento y lo general aparecen identificados con lo extenso ${ }^{43}$. Helvetius había expuesto antes esta misma tesis con su claridad habitual: «Entender por la palabra naturaleza el encadenamiento eterno y universal que vincula conjuntamente todos los acontecimientos del mundo, en el que la idea misma de azar se encuentra comprendida» ${ }^{44}$.

Y del mismo modo que los conceptos geométricos o mecánicos, los pilares de la nueva racionalidad (como sucedía con la categoría de la imputatio) eran descarnados y ahistóricos, susceptibles de ser utilizados igualmente en la física como en la ética sin cambiar sus propiedades; el nominalismo que estaba en la base del empirismo les prestaba valor universal. Precisamente esta única dimensión de los conceptos básicos, que los vol-

${ }^{41}$ Condorcet mantenía que el esquema general del mundo psicológico del ser humano es tan necesario por insertarse tan exactamente en el único esquema existente que debe ser llamado «métaphysique». Vid. N. DE CONDORCET, Esquisse d'un tableau historique des progrès de l'esprit bumain, Paris, Flammarion, 1988, p. 80. En cambio, el lenguaje que nos une a los hombres es cosa lograda «par des moyens artificiels» (p. 79).

42 Según algunos estudiosos Locke no fue materialista. Así lo afirmaba, entre otros muchos, David Hume. Vid. D. Hume, De la moral y otros escritos, traducción de D. Negro, Madrid, CEC, 1982, p. 170, $\$ 248$.

${ }^{43}$ G. W. F. HegeL, Lecciones..., op. cit., vol. III, p. 329. Christian Wolff lo explicaba en términos omnicomprensivos y aún rudimentarios: «La perfección de una cosa en general reside en la concordancia (Uebereinstimmung) de lo múltiple en uno, o de varios que están separados entre sí en una sola cosa. Esta concordancia es la determinación (Bestimmung) a través de la cual todo lo que es cierto tiene un destino común». Vid. C. WolfF, Grundsätze des Natur- und Völkerrechts worin aller Verbindlichkeiten und alle Rechte aus der Natur des Menschen in einem beständigen Zusammenhänge hergeleiten werden, Hallae im Magdeburgischen, 1754 , libro I, $\mathbb{\$}$. El título del libro es ya casi tan significativo en sí mismo como la cita expuesta.

${ }_{44}$ C.-A. Helvetius, De l'Esprit, op. cit., p. 326, nota a pie. El materialismo estaba sustituyendo la intuición de las formas por la imaginación de la materia en la imaginación o conciencia objetiva: solamente les resultaba una pura res extensa sin racionalidad. El problema radica en que esta res extensa es más pensante de lo que parece. 
vía comunes a todas las ciencias, parecía ser el garante de la cientificidad que reclamaban para sí las ciencias humanas ${ }^{45}$.

La conciencia, al convertirse en el objeto de sí misma, anticipaba sus propias leyes; y el filósofo, al faltar el criterio genérico del subjecta materia, explicó que estas leyes eran comunes para todos los sectores de la vida humana. La actitud mencionada, la del subjecta materia, era la de quienes entendían que cada cosa requiere de un camino distinto para ser conocida, y que sólo puede ser aprehendida hasta donde ella se deje dominar ${ }^{46}$. El científico premoderno era consciente de hallarse en un medio no creado enteramente por él, en el que su actitud era simultáneamente de amistad y de extrañeza; de ahí que Gandavus escribiera que «Philosophus est in mundo sicut filius in domo» ${ }^{47}$. El empirismo hubiera debido dejar a la conciencia nadar en los propios hechos entregándose a ellos por entero; pero el amor propio y los intereses obligaron a ser más positivistas que empiristas, normando a los hechos según leyes, pero en nombre de su simple descripción. Helvetius habló del Esprit para demostrar que no existe el espíritu; pero esta presentación de su tesis fue equívoca, porque nunca renunció al Esprit para abandonarse a los hechos. El empirismo siempre ha sido poco empirista.

\section{IV. ¿EXISTIMOS LAS PERSONAS?}

Desde esta unidad entre sujeto que conoce, objeto estudiado y leyes del estudio, la Modernidad —ya nos aludamos al jusnaturalismo propiamente moderno, ya al positivismo que se impuso en el siglo XIX— situó en virtud del método una circularidad en la que los elementos aparentemente fina-

\footnotetext{
${ }^{45}$ Condorcet explicaba que: «Ainsi, l'analyse de nos sentiments nous fait découvrir, dans le développement de notre faculté d'éprouver du plaisir et de la douleur, l'origine de nos idées morales, le fondement des vérités générales qui, résultant de ces idées, déterminent les lois immuables, nécessaires du juste et de l'injuste; enfin, les motifs d'y conformer notre conduite, puisés dans la nature même de notre sensibilité, dans ce qu'on pourrait appeler, en quelque sorte, notre constitution morale. Cette même méthode devint en quelque sorte un instrument universel; on apprit à l'employer pour perfectionner celle des sciences physiques, pour en éclaircir les principes, pour en apprécier les preuves; on l'étendit à l'examen des faits, aux règles du goût». Vid. N. DE CONDORCET, Esquisse..., op. cit., p. 223.

${ }^{46}$ Henricus Gandavus explicaba tardíamente que: «Unde cum impossibile sit quod eadem sit et aliqualis certitudo sciendi in omnia [...] impossibile est omnino quod sit idem modus sciendi, sive idem modus scientiam investigandi in omnibus». Vid. H. Gandavus, Summa quaestionum, Paris, 1520, art. 5, q. 5.

${ }^{47}$ Ibid.
} 
les adelantaban lo que podía ser dicho sobre la justicia; pues se trataba de crear doctrinalmente un poder que por el hecho de operar según las condiciones ya determinadas en la síntesis inicial, volviera justo lo decidido por él. Esta forma de proceder no representó a los moderni un problema especial, porque ellos entendían que dominaban los resortes de la racionalidad, ya que la representación moderna de la conciencia consistía en una conciencia de sí que se concibe absolutamente, de forma que el pensamiento puro aparece como algo que es frente a la conciencia, sin que permita alguna representación que se entienda que proviene más allá de ella. Ésta fue la intuición básica cartesiana: un ipsum esse subsistens que es pensamiento. De forma coherente, este filósofo negó la validez científica de los datos proporcionados por los sentidos y tomó como guía las leyes de la geometría y de la mecánica ${ }^{48}$.

Adelanto que no pretendo hacer un trabajo de historia de las teorías sobre la justicia; recurriré a la historia porque este recurso es necesario para entender el modo de trabajar de hoy en la elaboración de estos constructos o teorías, que es sustancialmente igual al de otros siglos; solamente ha cambiado algo la terminología, pero las trazas de las argumentaciones que presentan a estos conjuntos teoremáticos como científicos o requeridos de asentimiento, permanecen iguales: la imaginación humana es limitada.

Veamos el punto previo, el que exige la cientificidad para las elaboraciones racionalistas, que es el de la distinción entre el contexto de justificación y el contexto de presentación; para no confundir al lector con los términos que uso ahora, adelanto que entiendo que una realidad es el contexto de justificación, y otra los contextos de representación o de las representaciones. Pues si a lo expuesto concretamente en estos libros lo podemos llamar presentación, al método seguido para exponer eso lo podemos designar como regla de justificación o de validez. Pero reitero que para hablar con un mínimo de seguridad debiéramos contrastar el concepto presentado con el modo como alcanzamos ese concepto concreto, pues si aquel primer momento presenta, este segundo momento hace posibles esas representaciones plurales de las formas adecuadas a cada dato. Una cosa es, pues, el criterio universal de justificación o de validez (que no existe) y otra los contextos de las representaciones o los contextos de representación.

48 Vid. G. W. F. Hegel, Lecciones..., op. cit., vol. III, p. 276, donde escribe: «Descartes ve flotar ante él vagamente la idealidad y se halla muy por encima de la realidad de las cualidades sensibles, pero no pasa a la particularización de esta idealidad. Se detiene, pues, en el mundo de la mecánica en sentido estricto». 
La conciencia quedó convertida en su propio tema de estudio ${ }^{49} \mathrm{y}$, dada la unidad de lo que es al caso, el objeto estudiado, el sujeto que investiga y las leyes del conocimiento quedaron apresados en un único acto vital. Es razonable explicar que esto sea así, porque cada conocimiento concreto tiene mucho de configurador en el acto racional en el que es algo aprehendido. Pero algunos filósofos independizaron las leyes del sujeto y del objeto, y supusieron un mundo, nouménico de hecho tanto para Hume como para Kant, que normaba —normalmente limitándolas- las relaciones del hombre con su entorno. Tenemos derecho a preguntar que por qué motivo o motivos esta racionalidad es afirmada como objetiva o universal: la filosofía cartesiana, patente especialmente en sus derivaciones más tardías, se mueve en una especie de argumento ontológico que no alcanza solamente a Dios, sino ante todo a la universalidad del noúmeno en que supone que consiste el universo, lo que implica además que el universo racional es transparente al hombre ${ }^{50}$. Reiteremos: ¿de donde surgía y cómo fundamen-

${ }^{49}$ Hay que agradecer la claridad de Locke cuando indica expresamente que él sitúa sobre su entendimiento. Vid. J. Locke, «Essay...», op. cit., p. 4. Poco más adelante, en la p. 13, declara que expondrá en su obra una copia de su mente.

50 Este hecho lo seguimos observado hoy: autores como Maturana, Luhmann, Teubner o Habermas no cuestionan en ningún momento el carácter empirista —al menos en un primer momento- de la ciencia. Un sector de teóricos del siglo Xx —entre ellos Luhmann o Habermas - imponen a la filosofía empirista como el cauce tasado desde el que ha de partir todo el que reflexione sobre la ciencia, también sobre la ética. Sucede que todo materialismo tiene una vertiente necesariamente trascendente, por lo que podemos hablar de la trascendencia de la materia o de un espíritu absoluto que vive en ella. Un materialismo sin capacidad trascendental es insuficiente teóricamente. Cuando Apel y Habermas afirman sus noúmenos no contradicen lo que son en sí sus teorías, sino lo que ellos explican —a su propia costa - cuando establecen sus bases empiristas. No en falso explicaba Lorimer que al utilitarismo le falta un bomo noumenon kantiano, porque si no desemboca en un puro solipsismo. Vid. J. Lorimer, The Institutes of Law, 2. ${ }^{a}$ ed., Edinburgh, 1880, p. 51.

Es propio de los empiristas entender que desde el dato de la igual libertad es preciso establecer una regla de traducción general que, como en cualquier función proposicional en ese contexto, pueda ser transformada en una función proposicional concomitante en la que aparecen otros conceptos. En tal caso, construir un concepto sobre otros conceptos (pensemos en construir la justicia partiendo desde la igualdad) es indicar la definición construccional o constitucional que ha de ser realizada sobre la base de esos otros conceptos: ésta sería la esencia del más exquisito constructivismo.

Pero reparemos en que esta conciencia que sabe construir supone un yo innato y universal que construye las interpretaciones de sus experiencias: ¿son innatos los algoritmos? Un constructivismo radical habría de mantener que los elementos del conocimiento están en las mentes de las personas y que los sujetos no pueden obrar de otro modo; entonces habría que suponer que el hombre se adapta a su entorno mediante su conocimiento, de modo que esta adaptación sería la única razón de ser de lo conocido. Pero una explicación así nos llevaría otra vez a la oposición entre sistemas cerrados y sistemas abiertos, sobre la necesidad de que los sistemas hayan de ser pensados en un primer momento como cerrados para, más 
taron este noúmeno omnipresente? Locke explicó que provenía del power of things, pero él atribuyó también tantas capacidades configuradoras del conocimiento a la mente humana, que esta explicación le quedó insuficiente. No pudieron explicar las fuentes y el fundamento de los criterios de validez de las teorías epistemológicas que proponían. Podríamos hablar de presencia, de inmediatez, de instantaneidad, etc., como criterios decisivos para entender sus propuestas ${ }^{51}$, pero lo cierto es que elaboraron cuerpos doctrinales que superaban con mucho lo que podían ofrecer la presencia instantánea de los objetos. Hobbes se comportó como un investigador inmaduro cuando separó los laws of reason del resto de las manifestaciones de la humanidad. El más incongruente fue David Hume, quien en realidad ironizó sobre sí mismo, pues no fue capaz de percibir que su cuestionamiento de los «objetos» percibidos arrastraba consigo la negación de sus propias capacidades investigadoras. El teórico de la ciencia que introdujo honestidad more germanico fue Kant cuando propuso ese Entendimiento o Verstand a priori que normaba el conocimiento de todos los hombres individuales $^{52}$. Eran lógicos estos planteamientos: en la teología, tanto Descartes como Kant únicamente admitieron el argumento ontológico ${ }^{53}$.

Si concretamos este discurso descartando expresamente otras facetas y adaptamos este reproche al tema que quiero tratar, tenemos derecho a preguntar que dónde está ese punto en el que el sujeto se capta él a sí mismo siendo simultáneamente pensamiento objetivo y ser individual. Descartes adoptó una actitud incoherente, pues tenía que haber optado entre el radical ego cogito o los siempre precisos cogitata impersonales; desde el yo pienso no se deduce ningún mundo lógico objetivo ${ }^{54}$, y desde el mundo

tarde, o simultáneamente, mantener que son abiertos porque reciben conocimientos con los que elaboran la información gracias a la que sobreviven.

${ }^{51}$ Sobre la necesidad de la instantaneidad en Hobbes vid. T. HobBEs, Human nature, or the Fundamentals Elements of Policie, en The Works of John Hobbes, London, 1840, p. 15.

52 Éste es un punto difícil en Kant, porque él fue deliberadamente ambiguo cuando atribuyó ese recipiente de principios al psiquismo humano; en realidad él no proponía una introspección de tipo psicológico —en cuyo caso sería lícito hablar de psiquismo-, sino que lanzó un mundo categorial a priori en el sentido estricto del término, que le distanció decisivamente de sus maestros Leibniz y Wolff, a los que él reprochaba haber propuesto solamente una síntesis retórica, no verdaderamente trascendental.

Cuando Fiche se presentó modestamente, pidiendo disculpas por pretender ofrecer la verdadera interpretación de Kant, únicamente mostraba la modestia personal de la que hizo gala en el resto de su vida; en este punto —el de la modestia — sí se distanciaron verdaderamente él y Kant.

53 Sobre el argumento ontológico en Descartes vid. R. DesCARTES, «Seconde Méditation», op. cit., pp. 289-290.

54 Entre nosotros, García Suárez ha mostrado la imposibilidad de superar este solipsis- 
lógico universal y por ello impersonal no se llega al yo, que en principio es incomunicable por irreductible. Cabalmente, Descartes pretendió una filosofía de esencias matemáticas, según su sueño de la matemática universal $^{55}$, que no podía dar razón de las existencias siempre concretas. Una consecuencia de este planteamiento es que el hombre ha de vivir dejándose guiar sólo por esta racionalidad que cree contemplarse a sí misma.

Este mundo tan intelectual, nouménico, perdió de vista a las personas, pues los seres humanos somos las «cosas» máximamente no reconducibles a un esquema objetivo o universal, hecho que vemos especialmente claro en las explicaciones medievales cuando indican que las tres notas constitutivas de la personalidad son la incomunicabilidad, la soledad y la dignidad. Juan Duns Scoto escribía que cada persona constituye la última soledad del $\operatorname{ser}^{56}$. Los autores más recientes que se han embarcado en las naves empiristas no usan la expresión de persona, pero es más que patente que ésta es la imagen del hombre que tienen permanentemente ante su vista Isaiah Berlin o Jürgen Habermas en el momento de redactar sus obras ${ }^{57}$.

mo personal-lógico, aunque referido a los empiristas. Pero su crítica vale igualmente para Descartes. Vid. A. García SuÁrez, La lógica de la experiencia. Wittgenstein y el problema del lenguaje privado, Madrid, Tecnos, 1976, pp. 20 y ss.

Es lógico que se haya planteado reiteradamente esta objeción. Hegel descalificó sin más a los ensayos empiristas denunciando esta imposibilidad. Explicó que: «Lo que yo siento solamente es mío, me pertenece a mí como individuo particular; pero como la lengua expresa siempre lo universal, yo no puedo expresar lo que es un sentimiento mío exclusivamente. Lo que no puede ser nombrado ni comunicado, es decir, las sensaciones y los sentimientos, no es lo que hay de más importante ni más real; es, por el contrario, lo más insignificante y lo menos verdadero. Cuando yo digo: lo individual, este individuo, aqui y ahora - todas estas frases son universalidades, y bien que por todos y cada uno, aunque se trate de un aquí y abora sensibles, se quieren designar cosas individuales, todas estas palabras designan lo general—». Vid. G. W. F. HeGEL, Enzyklopädie der philosophischen Wissenschaften, Zweiter Teil, $\mathbb{} 254$ (cito por la edición de Frankfurt am Main, Suhrkamp, 1970, \$20. La traducción es mía).

Lo extraño es que el siglo xx haya vivido con esta contradicción y que solamente haya sido denunciada cuando el neoempirismo había caído bajo sus propias insuficiencias.

55 Estas deducciones se componen de teoremas, y podemos preguntarnos si los pasos argumentativos que permiten avanzar teóricamente a tales teoremas tienen naturaleza lógica, geométrica, matemática, de utilidad, de conveniencia según el fin ya propuesto. Ningún autor de los siglos XVII y XVIII que yo conozca trató este tema. Se lo plantearon expresamente Peano y, más temáticamente, Frege. Aun así, no parece que haya acuerdo, y nuestros silogismos viven ahora en el mismo estado asilvestrado que hace siglos.

${ }_{56}$ «Quia ad personalitatem requiritur ultima solitudo sive negatio dependentiae actualis et aptitudinalis ad personam alteri naturae». Vid. J. Duns Scoto, Super Tertio Sententiarum, Lyon, 1530, L. III, q. 1, art. 3.

${ }^{57}$ Como la persona así entendida es inargumentable desde los esquemas más generales y obvios que ellos siguen, los seres humanos permanecimos inexplicables en un universo movido de hecho por leyes mecánicas, fundamentalmente por la ley de la igualdad en la acción-reacción: ¿qué quedaría de Habermas o de Rawls si prescindiéramos del esque- 
Pero en las teorías la primacía la tiene el bomo noumenon afirmado a prio$r i$, y la persona concreta aparece como un apéndice de aquel noúmeno, pero sin que estos filósofos expliquen la razón por la que la persona emerge como un ser autoconsciente o libre. Pues parece que la persona es aquel ser que irrumpe en la vida con su propia oferta y que, al mismo tiempo que está sometida a leyes que determinan en buena medida su actuación, trasciende esas leyes mediante una autonomía que no puede ser explicada desde esas legalidades; esta autonomía no es necesariamente la del género humano en su conjunto, o la propia de cualquier moral positiva, sino también la que apunta a la espontaneidad y a las decisiones reflexivas de los seres humanos concretos, a veces irreductibles a órdenes de legalidad previamente establecidos ${ }^{58}$.

Fueron comprensibles la reacción kantiana y las filosofías personalistas posteriores, porque la negación de las personas hecha desde bases fenomenistas o idealistas produjo, como por un movimiento pendular de la afectividad, la afirmación de la máxima libertad de los hombres, y Kant hubo de acuñar dos términos nuevos: el de persona en el contexto de la moralidad, y el de persona jurídica o juristische Person ${ }^{59}$ para explicar el Derecho. En ambos casos, la Person presentada es ante todo libre, aunque la autonomía moral kantiana poco tiene que ver con lo que muchos entien-

ma que subliminalmente nos presta esta ley? Desde el siglo XvIII a hoy casi nadie se atreve a hablar de personas, y los que sí se refieren a ellas hacen esto porque han asumido un tono religioso o confesional, normalmente católico.

${ }_{58} \mathrm{La}$ circularidad a la que aludía líneas arriba la apreciamos de forma especialmente clara en los elementos finales kantianos, los que orientan la creación de su sistema universal de fines: las exigencias abstractas requeridas para fundamentar la existencia del orden moral objetivo o la inmortalidad del alma adelantaban, en virtud del propio método, lo que podía ser dicho sobre la filosofía práctica. Algunos filósofos mantienen que Dios, en Kant, es sólo un parásito de la moral, y lo mismo podríamos decir de la persona humana. Si salimos del campo de la filosofía de la ciencia y de la moral — que es donde Kant nadaba más a gusto-, y atendemos a su metafísica del derecho (Metaphysik des Rechts), vemos también claramente el funcionamiento de esta síntesis a priori. Kant establece «personas», llamadas personas jurídicas que han de realizar por sí mismas un orden moral objetivo, pero al reservar todos sus esfuerzos para la moral, al de Könisberg le faltaron las fuerzas y los recursos argumentativos para explicar el Derecho.

Este aparece en su doctrina únicamente como una coacción socialmente organizada que trata de buscar las mayores esferas posibles de libertades individuales, pero era una explicación simplificadora en exceso, porque el orden jurídico que vivimos realmente todos los días no se limita simplemente a hacer posible el respeto a nuestro plan de vida personal. Además, la igual libertad ha de operar en unos momentos y no en otros, pues si se destruye en algunos momentos la igualdad, lo procedente es explicar que el principio de la igualdad no es completo en sí mismo, tomado de forma absoluta.

$59 \mathrm{Vid}$. mi artículo «La independencia y autonomía del individuo: los orígenes de la persona jurídica», Anuario de Filosofía del Derecho, núm. 4 (1987), pp. 477-522. 
den bajo esta expresión. Es cierto que el momento histórico en el que vivía Kant había tasado sus posibilidades argumentativas: bajo la visión newtoniana del mundo, la naturaleza era el ámbito de la necesidad o Notbwendigkeit (sigo la grafía alemana del siglo xvIII), de leyes que se cumplen inexorablemente; por el contrario y dialécticamente, el mundo humano había de ser el mundo de la libertad o del arbitrio ${ }^{60}$. Pero ni Kant ni sus discípulos estuvieron en condiciones de explicar cómo surge el arbitrio individual desde el orden ideal a priori. No es que no lo explicaran de hecho, sucedía más bien que sus axiomas les vedaban tal explicación. Kant recurrió al hecho innegable del deber para derivar desde él, postulándola, la realidad y objetividad del mundo moral, y esta base para el arranque de su doctrina sobre la moral constituyó sin duda un axioma válido no solamente en el conjunto de su teoría, sino también para las teorías éticas de todos los tiempos. Pero es difícil conciliar el mecanicismo universal en el que él creía con la incomunicabilidad de las personas. De hecho, estamos autorizados a preguntar: ¿cuál puede ser el puesto del ser humano en el mundo de Newton? Del mismo modo que Dios, la persona quedaba fuera del mundo, y así como hablamos de un Deus ex machina, podríamos hablar de una Homo extra machinam ${ }^{61}$.

Kant se había dejado llevar por la intuición básica de Rousseau, al que él llamaba el Newton del mundo moral. Rousseau no creía en la ley moral en el sentido usual de la expresión, ni en la ley natural, en el sentido más corriente en el Iluminismo. Tampoco creía en las personas como seres solitarios e incomunicables. Su doctrina ética fue, más bien, el intento más radical hasta entonces para mostrar la moral como cosa universal, en la que naufragaban las voluntades e inclinaciones individuales; estas inclinaciones individuales únicamente formaban la volunté de tous, es decir, la voluntad realmente expresada, que había de ser rechazada en el plano de la teoría moral porque los hombres somos malos. Opuso la idealidad siempre objetiva de la voluntad general a las voluntades efectivamente existentes; la abstracción engulló a las particularidades individuales. Kant quedó influido decisivamente en este punto, y condenó los

${ }^{60}$ Es sintomático que estos filósofos, que historié en La Cabeza de Jano, usaran siempre el término «arbitrio» («Willkühr») y no el notablemente más complejo de «libertad» («Freibeit»).

${ }^{61}$ Llano destacó la disolución de la persona en el pensamiento kantiano. Vid. A. LLANo, La nueva sensibilidad, Madrid, Espasa-Calpe, 1988, p. 98. Fue lógico que Kelsen, imbuido en el mundo casi-nouménico de las normas, explicara que la persona jurídica es sólo el punto de «atribución» («Zuschreibung») de un sector de las normas del ordenamiento jurídico. Vid., por ejemplo, H. Kelsen, Reine Rechtslebre, op. cit., $\mathbb{\$} 37$, p. 192. 
«móviles» que llevan a los hombres realmente a actuar (a los que designó algo despectivamente con el término Triebfeder) con la verdadera voluntad universal.

Rousseau presentó a unos individuos indiferentes unos a otros en el estado de naturaleza, que solamente alcanzaban la eticidad o moralidad a través de un nervio de su existencia social. Este nervio no podía ser la personalidad individual (ésta sería más bien en él el principio de toda injusticia) ${ }^{62}$, sino aquel interés verdaderamente común de la humanidad que llegamos a conocer despojando a los seres humanos de sus particularidades $^{63}$. Las personas no eran reconocidas como tales, sino que únicamente componían esa materia bruta del Derecho que le era imprescindible para componer su teoría ética que abocaba a la voluntad siempre justa e igual para todos. La síntesis a priori roussoniana adelantaba unos seres humanos que sólo tenían «sentido» desde la visión final del sistema ético propuesto. Es cierto que algunas obras suyas tienen un tinte más personalista, pero en el $\mathrm{Du}$ contrat social expuso bastante rotundamente este pensamiento, tal como destacó Jellinek polémicamente ${ }^{64}$.

En cualquier caso, tomemos a los empiristas, a Kant o a Rousseau, permaneció como ocupación propiamente científica el estudio de un único corpus de normas. Esta exigencia arrastraba tras sí otras dos: una, la primacía del corpus logicum sobre el estudio de las personalidades; la otra, la primacía del estudio formal de los nervios de ese cuerpo sobre el análisis y síntesis de las exigencias de las situaciones concretas que tal conjunto de normas regula. La primera negaba a las personas, y la segunda a las posibilidades de la ontología. Porque las doctrinas de los siglos XVII y XVIII ante todo quisieron explicar en términos unitarios la génesis y operatividad de los conjuntos jurídicos, de forma que la misma nota que hacía injusta a una determinada hipoteca dictara la injusticia de la actuación de un padre con sus hijos. Esta excesiva sectorialidad, al chocar con esta pretensión universal, hizo que las opiniones se dividieran en el momento de determinar cuál

${ }^{62}$ Los moderni habían insistido en la philautia o amor a sí mismos como el rasgo distintivo y orientador de las actuaciones individuales. Por tanto, todo lo que pusiera amistosamente - por así decir - en contacto a un hombre con otro no podía consistir en disposiciones o actuaciones personales (transidas de egoísmo por definición), sino en algún tipo de orden lógico o nouménico que supliera lo que falta en las personalidades reales. Hobbes dio ejemplo de este tipo de argumentación al corregir al jus naturale a través de los laws of reason.

${ }_{63}$ Un tema que no aborda Rousseau es la diferencia hegeliana entre particularidad o Besonderheit y peculiaridad o Einzelheit.

${ }^{64} \mathrm{Vid}$. G. JeLLINEK, Die Erklärung der Menschen- und Bürgerrechte, München-Leipzig, Duncker und Humblot, 1927. 
había de ser ese factor que reclamaba para sí a todas las fuentes de la justicia $^{65}$. Las relaciones entre las personas y el ordenamiento jurídico fueron explicadas por principios teóricos, no prácticos ${ }^{66}$, que trataban de exponer la génesis en la razón del orden jurídico como tal. En vano, por lo general, buscaremos en ellos referencias a la justicia que podría ser reclamada por las personas en tanto que personas, en nombre de las concreciones de su dignidad genérica, o de sus necesidades diversas. Estamos ante dos planos. Uno es el de las personas, que escapa al estudio de la ontología porque la ontología no puede dar razón de la universalidad que porta todo ser humano. El otro es el de las determinaciones de las personas con las cosas, porque al Derecho no le interesa únicamente saber que soy una persona, sino que también se interesa por cuánto gano y sobre si estoy casado. Este segundo momento sí es el de la ontología en el Derecho. Es un momento difícilmente apreciable por quienes centren sus estudios en la universalidad de la persona, etc., sin tener en cuenta la intuición que guiaba a Tomás de Aquino cuando escribía que «Persona est homo larvatus» ${ }^{67}$, ya que a la persona le son tan humanas sus determinaciones como su universalidad.

${ }^{65}$ Grocio y Pufendorf habían hablado confusa y contradictoriamente de fomentar la sociabilidad, motivo por el que un sector de la doctrina alemana del siglo XvIII los conoció como los «socialistas». Thomasius recurrió al vivere diuturne et foelicissime como fin último que concedía sentido a todo el derecho. Locke habló de fomentar la libertad en el uso y transmisión de las propiedades privadas según lo que él llamaba la Ley Fundamental de la Sociedad. Diversos teóricos alemanes hablaron del Estado de Derecho (Rechtsstaat), porque entendían que la función de la sociedad política era la de proteger los tres Urrechte o derechos fundamentales del ser humano - la propiedad, la libertad y la igualdad - que peligraban en el estado de naturaleza; usaban la expresión Urrechte y no la más precisa de Menschenrechte porque una sentencia del Reichcammergericht había prohibido su uso por sus connotaciones demasiado innovadoras.

${ }^{66}$ Sobre las acusaciones de sustituir los principios prácticos por los teóricos vid. L. Cabrera Caro, Modernidad y meoescolástica: Anselmo Desing, Cádiz, Servicio de Publicaciones de la Universidad de Cádiz, 2001, pp. 182 y ss.

${ }_{67}^{6}$ T. De Aquino, In IV Sententiarum (In Primum et Secundum Sententiarum), en «Opera Omnia», Tomus Sextus, Romae, 1570, L. I, Dist. 23, q. 1. Es lógico que más tarde explicara en Suma teológica I, q. 29, art. 1, que la persona es la substantia prima de Aristóteles. En todo este tema anda en juego su noción de conciencia y consciencia personal como Cum alio scientia. Vid. Suma teológica, I, q. 31, art. 3, o In IV Sententiarum..., op. cit., L. II, Dist. 24, art. 2.

Austin destacó reiteradamente que, en primer lugar, hay que estudiar el derecho de cosas y sólo después el derecho de personas. Vid. J. Austin, Lectures on Jurisprudence or the Philosophie of Positive Law, 5. ${ }^{a}$ ed., London, John Murray, 1911, p. 721, entre otros muchos lugares. Su tesis más básica es que las cosas determinan el alcance del derecho de cada persona (p. 46). Efectivamente, mis posibilidades personales vienen determinadas por mis condiciones de profesor o conductor. No en vano opinaba Lorimer, citando a Hegel, que la jurisprudence es de algún modo el reino de la libertad realizada. Vid. J. LoRIMER, The Institutes of Law, 2. ${ }^{a}$ ed., Edinburgh, 1880, p. 2. 


\section{LA DIVERSIDAD DEBE RECLAMAR SUS DERECHOS}

El investigador renuncia a descubrir una imagen unitaria del mundo. Heidegger denunciaba que las expresiones imagen del mundo e imagen moderna del mundo mientan el mismo hecho, porque sólo el hombre moderno se hizo la ilusión de poder entender conjuntamente lo que vive ${ }^{68}$. Sabemos que esta ilusión vino de las esperanzas que suscitó el nuevo método científico; y sabemos que estas esperanzas no se han mostrado - al menos aún- fundadas. Incluso en el tema más básico, los dos científicos quizá más relevantes del siglo Xx discreparon ásperamente: según Einstein, la lógica sólo admitía el es/no es; y Planck mantuvo la necesidad de la lógica trinómica: es/no es/puede ser. La uniformidad de otros tiempos ha perdido su base científica.

Pero la pretensión de lograr la unidad científica, con su imagen única o unitaria del mundo implicada, es mucho más que una aspiración simplemente cognoscitiva o teórica. La ingenuidad científica a la que he aludido en otros momentos estaría tentada a pensar que, puesto que pasó el momento de la unidad, la diversidad debe ahora reclamar sus derechos. Pero el hombre que surgió desde el Iluminismo es apasionado, y así como la Inquisición procesó a Galileo cuando era patente a todos que la verdad estaba en la afirmación del sistema solar, el espíritu colectivo todavía dominante reclama la reductio ad unum de nuestra visión del mundo. Incluso las teorías actuales sobre el caos siguen esta mentalidad. Hoy, la mentalidad veteromecánica está siendo sustituida por la sistémica; pero Luhmann o Teubner siguen dependiendo de la representación imaginaria de esa protorrealidad omnipresente que adopta formas distintas en sus cambios; mantienen que las mutaciones siguen los movimientos intracelulares: permanecen en el interior del esquema binómico, al que no pueden abandonar sin renunciar a su materialismo fácil. Ellos entienden que el significado del Derecho consiste en ser una función que solamente toma funciones como su argumento, es decir, una función que tematiza un conjunto de funciones, de forma que lo explicado satisface solamente a una cierta condición del entorno según razones de oportunidad y de exigencias de diferenciación. Pero, también frente a los sistémicos, es preciso reconocer que la complejidad persiste. Somos ya conscientes de que las simplificaciones se refieren a realidades que funcionalmente son realmente complejas; incluso permane-

68 Vid. M. Heidegger, «La época de la imagen...», op. cit. 
ciendo en un plano próximo al empirismo, no parece lícito explicar con las mismas leyes unos procesos que siguen leyes de índoles distintas.

Es preciso insistir en que las leyes que nos gobiernan tienen naturalezas diversas. La capacidad científica suficiente para hacer la tabla periódica de los elementos ha creado la ilusión de que todos los procesos, minerales, vegetales, animales y humanos, pueden ser explicados en términos de combinaciones (por decirlo así) de esos elementos. Esta afirmación es tan cierta como insuficiente. Hobbes negaba la libertad del hombre indicando que es la última deliberación la que arrastra al apetito ${ }^{69}$, pero todas las escaleras tienen un escalón último, sin el cual no pueden ser pensadas. El investigador ordena y expone sus ideas gracias a diversos instrumentos de escritura, pero no piensa que sus estudios serán distintos según que use la pluma estilográfica o un bolígrafo. Es lamentable que los bolígrafos hayan sustituido, también en los trabajos más sedentarios, a las estilográficas: nada iguala a la viveza y a la fuerza del trazo hecho con la pluma. Pero, a pesar de la verdad de esta afirmación, el investigador sabe que el uso de uno u otro instrumento no determina lo que expondrá finalmente.

Abusando de la paciencia del posible lector, he de indicar, otra vez, que rompo una cierta linealidad presumible porque quiero descartar más opciones para retener la que me interesa ahora. Ya que estoy hablando de la unidad conseguida por el viejo método científico entre sujeto, objeto y mundo intelectual, y de las esperanzas que aún hoy suscita la posibilidad de alcanzar esta unidad, saco a colación la discusión sobre la posibilidad de acceder a un corpus logicum de validez ${ }^{70}$ indiscutible, o al menos difícilmente discutible, cuyo conocimiento nos explique lo que es y ha de ser la reflexión sobre el Derecho. En otras palabras, quiero cuestionar los intentos de establecer una Teoría del Derecho, tal como las redactaron Knapp, Bergbohm, Kelsen, Bobbio, Hart o Dworkin. Estos autores fueron positivistas, y el positivismo nació y se desarrolló de la mano de «teorías», es decir, de explicaciones compactas, coherentes y transmisibles intersubjetivamente con cierta facilidad. Las teorías, siempre de la mano de una ima-

${ }^{69}$ Las negaciones que hace Hobbes de la libertad son numerosas. Vid., por ejemplo, Leviathan, or the matter, form and power of a Commonwealth eccliastica and civil, London, 1839 , p. 32, o Elements of Philosophy, op. cit., pp. 408-409. La idea expuesta arriba se corresponde literalmente con lo que él expone en Human nature..., op. cit., p. 68.

${ }^{70}$ El criterio de validez del derecho dista de estar claro. Ante todo, el lector puede advertir que lo que llama contexto de justificación o de validez de una teoría es una realidad más amplia que no el criterio estrictamente jurídico de la validez. Para una clarificación de esta expresión vid. J. Delgado PINTO, «La validez del derecho como problema de la filosofía jurídica», en Estudios de filosofía del derecho, Madrid, CEC, 2006, pp. 193-236. 
gen del mundo más amplia que está en su base, han pivotado sobre las limitaciones que establece un plano de justificación aceptado sin discusiones y, normalmente, sin matizaciones. Las teorías jurídicas positivistas han sido posibles desde la negación de cualquier justicia de alcance universal. Recordemos las palabras de Bergbohm: «Nos preguntan si no "sentimos" que hay que cumplir la palabra dada, respetar la propiedad ajena, castigar a los malhechores, etc. Esta manera falsa de generalizar no tiene sentido. Nadie, absolutamente nadie, siente igual» $\gg^{71}$. En un segundo momento, estas explicaciones sitúan el límite entre lo normativo y lo no normativo jurídicamente en lo que alcanza a normar un criterio de validez intrametódico: podemos llamar positivistas a todas las explicaciones sobre la estructura o la función del Derecho que establecen que será Derecho lo que dicte el rey, el papa, el emperador, el Parlamento. He tocado este tema en otros momentos ${ }^{72}$, y mi intención ahora es tratar de profundizar, de modo más abstracto, en la estructuras de las Teorías del Derecho, no criticar las pretensiones de un criterio solitario de validez.

\section{La pretensión sistemática}

Tratar este tema es asunto complejo, porque no partimos desde cero: la historia nos ha dejado diversos tipos de explicaciones sobre el Derecho, y también varias clases de modos argumentativos, más amplios, para construir una explicación sobre la filosofía práctica. Quiero poner el dedo en esos «modos argumentativos» al filo de los cuales hemos ido construyendo las teorías jurídicas y en general prácticas. El lector puede retener la distinción, de pedigree kantiano, entre doctrina y teoría: ya sabe que, aunque no sigo a Kant, distingo la una de la otra. Una teoría es una propuesta lógico-intelectual que sirve para explicar alguna realidad; no nos interesan las explicaciones sobre el tipo del movimiento que estudian los físicos, sino las explicaciones sobre los movimientos o problemas humanos en tanto que humanos, es decir, en tanto que intencionales por racionales. Un problema

\footnotetext{
71 «Sie fragen uns, ob wir es denn nicht "füblten", das Versprechen gehalten, fremdes Gut respektieren, Übelthäter bestraft werden müssten und dgl. Diese einerseits abstrakte falsch generalisierende Weise verschliesst jedoch den Weg zur Einsicht. Niemand, schlechthin niemand "füblt" dergleichen». Vid. K. BERGBOHM, Jurisprudenz und Rechtsphilosophie, Leipzig, 1892, p. 467.

${ }_{72}$ Vid. mi artículo «Regla de reconocimiento, o contexto de reconocimiento», en El positivismo jurídico a examen. Estudios en homenaje a José Delgado Pinto, Salamanca, Universidad de Salamanca, 2006, pp. 171-195.
} 
es, en última instancia, una insuficiencia: puede que sea una insuficiencia en los medios necesarios para alcanzar un fin, o la ausencia de un criterio claro para resolver la perplejidad que suscita alguna antinomia. Las teorías consisten en esas propuestas intelectuales que determinan la selección de los criterios para resolver toda una clase de problemas. La exigencia propiamente sistemática provoca la expulsión del estudio de los problemas que no pueden ser reconocidos como tales según las limitaciones puestas por el sistema, y en tal caso los sistemáticos o positivistas dirán que un problema no es jurídico, sino que responde a un simple interés, o que es de naturaleza moral. El positivismo es la actitud de quienes, ante todo, excluyen. Pero los positivistas no acaparan el uso de las técnicas para crear teorías: la explicación de Kant sobre la ciencia expuesta en «La doctrina de los elementos» es sistemática, y lo mismo sucede con sus argumentaciones sobre la filosofía práctica, en general, que expone en la «Dialéctica trascendental».

Recapitulemos, al modo como va haciendo Husserl continuamente en sus «Meditaciones cartesianas». Tomemos a Kant como banco de pruebas. Tenemos en él un constructo intelectual, varios problemas definidos que buscan su explicación, y un modo de argumentar que él va desgranando según las reglas de ese constructo, y que tienden (es su razón de ser) a resolver esos problemas. Nos interesa la estructura de esos «modos de argumentar», es decir, de los puntos de referencia que él usa, y cómo los usa para resolver sus tres problemas: el de la demostración de la existencia de una moral de validez objetiva, el de la inmortalidad del alma y el de la existencia de Dios.

En su «Dialéctica trascendental» propone la existencia de un «sistema de fines» en fuerza del cual nada puede existir aisladamente o sin sentido: es así que existe el deber, luego han de existir «las cosas» que requiere el deber. Él hace encajar cada paso argumentativo concreto en un sentido superior que proviene desde ese sistema universal de fines. La segunda y la tercera parte de su Crítica de la razón pura, a las que llamó «Dialéctica trascendental» y «Sistema trascendental del método», componen textos extremadamente argumentativos. Kant ha sido el filósofo por excelencia de la argumentación abstracta; a su lado, Tomás de Aquino o David Hume pecan por excesivamente intuitivos y por ello necesitados de más reflexión. La forma argumentativa que él usa más es la de suponer que la distancia o el espacio que media entre la existencia del deber y la regla moral objetiva que hace posible el deber no puede quedar sin explicación, pues no existen vacíos: «non datur vacuum formarum» ${ }^{73}$. Luego es necesario que exis-

73 Un aristotélico nunca hubiera aprobado este modo de proceder en la ciencia. Tomás 
ta una explicación racional que explique el paso desde el deber a la regla y desde la regla al deber. El lector de estos textos suyos «ve», de una forma prácticamente táctil, cómo la existencia de una realidad provoca como una succión que arrastra tras de sí la necesidad de las existencias (nouménicas) de las realidades que son necesarias para que exista aquella primera cosa afirmada. Las expresiones que más usa son el «es necesario» y el adverbio «necesariamente»: es necesario que si existe $C$ haya de existir B. Afirmando las existencias de las cosas que requiere una afirmación, forma sistemas de sentido locales, y finalmente todos ellos han de encajar en un «sistema universal de fines». Nada existe a modo de un verso suelto: si existen versos es porque ya existe necesariamente el poema completo. Procediendo de este modo expone un corpus logicum extremadamente coherente y que, cara a los lectores más incautos, presenta la ventaja de que no es fácilmente comprensible.

En realidad, Kant siguió el método de los físicos teóricos de su tiempo, porque, completando lo que sabemos que es con lo que ha de ser para explicar la existencia y operatividad de aquella primera realidad, diseñó un sistema especialmente completo, es decir, singularmente coherente y omnicomprensivo. Parece que es una inclinación la razón humana descansar más plácidamente cuando reposa sobre un sistema suficientemente lógico y que aleja de sí lo que no puede ser explicado en él; desde luego, gana en seguridad subjetiva gracias al dogmatismo que adquiere. Y Kant, precisamente por atender al espíritu de la mecánica clásica —él creyó que constituía la explicación definitiva del mundo-, permaneció preso en las redes materialistas que imposibilitan entender la noción de persona. Sucede que esta mecánica atiende a legalidades universales sin que pueda explicar a lo concreto como tal. Ya aludí a los físicos que niegan todo lo que no pueda ser reconducido al esquema universal: lo que carece de la dirección impuesta por la legalidad en la que cada cuerpo debe insertarse es absurdo. La afirmación del único momento científico universal o formal creó una enorme negación que, como toda negación, dio origen a una universalidad simplemente negativa ${ }^{74}$; esta mentalidad, también conocida como mos geometri-

de Aquino mantenía que el movimiento solamente procedía ex natura, nunca ex vacuo. Vid. T. De Aquino, In octo libros Physicorum..., op. cit., $\$ 521$.

${ }^{74}$ Kant hizo de esta forma de postular las realidades el quicio de su filosofía. En la Crítica de la razón pura, op. cit., A 571, escribe que: «Toda cosa se halla igualmente, desde el punto de vista de su posibilidad, sometida al principio de la completa determinación según el cual tiene que convenirle uno de cada par de predicados opuestos, en la medida en que hayan sido confrontados con sus contrarios todos los predicados posibles de las cosas». 
cus, solamente afirmó el momento formal desvinculado de lo real en lo que vive. Pero la geometría, tan formal como negadora, se vio desgarrada por sus contradicciones internas, y Hegel se sintió en la obligación de explicar que el punto es la negación del espacio ${ }^{75}$. De forma paralela, la persona, que en cierto modo es el punto en el espacio, ya que es el ser-ahí o el ser-parasí, ha de ser negada permanentemente en el espíritu de la ciencia moderna.

\section{El espíritu sistemático}

El físico del siglo Xx ha tenido que renunciar a esa seguridad que proporciona una teoría cuando está bien construida según los patrones de la coherencia y la seguridad personal. Se ha de contentar con estar en condiciones de poder predecir grosso modo la trayectoria de un cuerpo. Le quedan problemas que no se dejan reconducir a una legalidad superior, y ya no piensa en que una profundización de la mano de los moldes metódicos heredados deshará los absurdos que él no puede explicar. La noción de ley (Gesetz) ha perdido su exigencia de universalidad y ha quedado como la descripción de algo meramente general: así lo mostró Franz von Weizsäcker en los ciclos de conferencias que dio sobre el impacto de la mecánica cuántica en la filosofía de Kant. Tomemos un ejemplo tan anecdótico como frappante: los artilleros de todos los tiempos saben que hay proyectiles que tienen voluntad propia porque no se someten a las tablas de tiro. Superficialmente se puede pensar que esas irregularidades se deben a una variación en la cantidad o calidad del explosivo o del proyectil, pero no es así: se trata de un problema teórico, no práctico. Desde el punto de vista práctico, esos tiros se pueden calificar de excepcionales, pero desde el punto de vista teórico, los tiros erráticos poseen su propia racionalidad, exactamente igual que los tiros más normales estadísticamente. Es decir, existen legalidades concretas no sólo no reconducibles a la leyes más generales dominantes en ese campo de la ciencia, sino opuestas a ellas.

Superamos el Caribdis de la ciencia al comprobar que no existe un método único que pueda dar cuenta, según los mismos criterios, de las leyes distintas. Aunque el científico divida y vuelva a subdividir, siempre se encontrará con que lo dividido sigue unos criterios de individua-

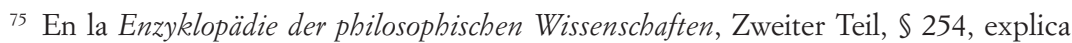
que: «Der Punkt, das Fürsichsein, ist deswegen vielmehr die und zwar in ihm gesetzte Negation des Raums» (cito por la edición de Frankfurt am Main, Suhrkamp, 1970). 
lización que se oponen a los de su género superior; lo que indica que no existe tal género anterior y más comprehensivo, y que el nuevo árbol de la ciencia ha de yuxtaponer lo que es distinto. Por esto, la fe en el Dios único ha derivado hacia el politeísmo. El jurista supera también la Scila cuando comprueba que no trabaja en el caos, porque el orden jurídico no es enteramente convencional, ya que sabe que cuando trabaja como profesor ha de explicar con claridad, y cuando conduce ha de conducir con prudencia. Supera esta mentalidad de verdades parciales que parece conllevar nuestra época ${ }^{76}$.

Los autores sistémicos han avivado un último chispazo del espíritu sistemático al proponer un esquema intelectual que daría razón, siquiera fuera muy formalmente, del comportamiento de lo que es. Luhmann, nada modesto en sus pretensiones, hace partir a sus consideraciones desde «Las tinieblas originarias» para llegar, de la mano del esquema del movimiento que él propone, a los sistemas actuales ${ }^{77}$. Surgen dos observaciones posibles: una, que estas explicaciones son inverificables, en todos los sentidos y alcances de este término; la otra, que la racionalidad binómica y siempre progresiva le trae sin cuidado al profesor cuando sabe que ha de preparar sus clases o que ha de conducir su automóvil de la forma que exige el trayecto que está recorriendo.

Es preciso seguir la orden de Hobbes cuando nos mandaba que fuéramos «realistas»: ¿acaso no nos hacemos acompañar de otros cuando viajamos? Seamos realistas, como nos ordena Hume en plena contradicción con

76 Ollero toca este tema tan elemental preguntándose si «¿ंexiste un fundamento "natural" capaz de justificar determinadas exigencias deontológicas, lleguen éstas o no a cobrar rango jurídico?, ¿son todas ellas, por el contrario, fruto de códigos convencionales, escritos o no? Si nos remitimos al ámbito de las profesiones sanitarias [...] queda fuera de toda duda que la elaboración de códigos éticos, o la formulación de protocolos indicativos de una parte de la praxis, no pretende tanto levantar acta de lo que masivamente se viene haciendo como establecer - ante una posible dispersión o multiplicidad de actitudes- lo que razonablemente deberá hacerse». Vid. A. Ollero, Derechos humanos..., op. cit., p. 83.

77 Luhmann se atreve a más y para abordar este problema él se sitúa en los inicios de todo, al modo del Libro del Génesis, y escribe que: «En las tinieblas originarias el mundo ya diferenciado presenta distinciones, discontinuidades y procesos de formación sistémica. Sólo en referencia a una diferencia ya dada puede el sistema elegir una estrategia de diferenciación ambiental». Vid. N. LuHmann, Fin y racionalidad en los sistemas. Sobre la función de los fines en los sistemas sociales, traducción de J. Nicolás Muñiz, Madrid, Editora Nacional, 1983, p. 186. Tesis atrevida, ciertamente, ya que Aristóteles solamente se atrevió a mantener la eternidad de la materia. Teubner sigue esta misma actitud, más moderadamente, y alude a los procesos moleculares que tienen lugar en las células y en los procesos neuronales del sistema nervioso. A falta del original, vid. la traducción italiana de A. Febrajo y C. Pernnisi, Il diritto come sistema autopoetico, Milano, Giuffrè, 1966, p. 42. 
el resto de su filosofía cuando trata de la justificación de las propiedades privadas: «Si observamos a los hombres en cada interrelación de negocios o de placer, en cada discurso o conversación, en parte alguna encontraremos, excepto en las escuelas, que se dude acerca de este tema» ${ }^{78}$. Si hacemos caso a este consejo tan imperativo hemos de reconocer que existen los otros, es decir, que la aparente sencillez de un discurso empirista oculta muchas cosas que no debieran haber sido veladas. Un investigador que presuma de ser filósofo «puro» no hará pie en el momento de introducirse en el mundo del Derecho; es posible que cuando trate de la verdad de un enunciado normativo quede empantanado en la literatura analítica del siglo xx; es más que posible que consuma su vida académica tratando de mostrar el sentido de una frase como «El cretense mentiroso dice que miente». Pero el investigador que hace profesión de jurista impone su aparente tosquedad sobre la superficial finura de las distinciones analíticas y explica, junto con Pedro de Bellapertica, que «Difficultates multiplicare non est solvere».

Efectivamente, la rudeza del que estudia Derecho le hace deshacer los nudos gordianos, pero no al modo de Alejandro, que cortó el nudo con su espada (según la leyenda), sino, más sencillamente, mostrando que esa dificultad puede estar resuelta en la cotidianidad. Reitero que el profesor sabe, en un plano normativo, que ha de explicar con claridad en el momento de la docencia, y que ha de conducir con prudencia en el momento de la conducción. Sabe también que estos dos deberes no se pueden explicar desde una teoría única que establezca una misma base y un solo cauce de desarrollo de las argumentaciones para explicar la justicia de ambos problemas. Este momento más de la concreción es el de la base ontológica de las decisiones sobre la justicia ${ }^{79}$. El investigador de

${ }^{78}$ D. Hume, De la moral..., op. cit., p. 132, $\$ 218$ (la cursiva es mía). En la cita transcrita se refiere a la utilidad como base de la moralidad. En la p. 173 de esta obra $(\$ 251)$ declara que las oscuridades que se observan a veces en la física no alcanzan al estudio de la moral, porque la moral se fundamenta en unas observaciones más sencillas que las de la física. Él suele partir desde el «hecho humano», cognoscible mediante la experiencia ( $v i d$. $\$ 187$ ), y dice frecuentemente que él sigue en su tratamiento de la ética un método verdaderamente «filosófico».

79 Podemos hablar de bases ontológicas, naturales, etc. Tanto da, la «naturaleza» no ha instituido la conducción de los automóviles, pero nuestra cotidianidad es lo más nuestro. Sir James Harrington reconocía la realidad de la intuición aristotélica: que la naturaleza se encarna en lo cotidiano. Vid. J. Harrington, Oceana and others Works, London, 1771 , p. 225. Una advertencia que hay que completar con la observación de Allen: que la ciencia jurídica no necesita de la ética ni de la metafísica. Vid. C. K. Allen, Legal Duties and other Essays in Jurisprudence, Oxford, Clarendon Press, 1931, p. 17. Lo que no le impide reconocer, en la p. 112 de esta obra, que la moral es el máximo fundamento del Derecho. 
estos temas, si se ocupa del Derecho, vuelve su vista hacia el casuismo porque comprueba la realidad de lo indicado: que conducir comporta sus exigencias propias y que explicar en clase comporta otras exigencias distin$\operatorname{tas}^{80}$, y que ambos tipos de normatividades no se dejan deducir desde un mismo dato o teoría porque proceden de contextos justificativos distintos. Un materialista que mantenga que no existen distintos powers encontrará más dificultades para explicar estos hechos plurales ${ }^{81}$. Efectivamente, existen muchos fines en el Derecho ${ }^{82}$, y es preciso admitir una heterogenia de los principios prácticos.

Quizá el investigador no se hubiera expresado así veinte años antes, cuando la comunidad universitaria estaba condicionada por las complicaciones que situaban los de Viena. Pero el hundimiento de la filosofía empirista, otra vez, en el siglo xx, le lleva a cuestionar con más facilidad las bases no sólo de Otto Neurath, sino igualmente las de Habermas, Rawls o Saussure. Cuando lee a David Hume (que fue el investigador al que en definitiva hay que reconducir estos intentos) le extraña comprobar que al final de su Tratado sobre el conocimiento bumano condene a la papelera a los libros escolásticos porque los argumentos de estos libros no están montados sobre las posibilidades argumentativas de los números y de las figuras. Le extraña esta condena porque Hume publicó dos libros relativamente extensos, el ya citado y su Tratado de la naturaleza bumana, sin hacer ninguna referencia a la geometría ni a la matemática. Su escándalo se agudiza cuando comprueba el trato tan diferente que Hume otorga, en sede científica, a las leyes científicas y a las propiedades privadas: es patente que este teórico de la ciencia, como todo escocés juicioso, tenía muy presen-

${ }^{80}$ Según Smith, el casuismo se debió a la influencia «papista» a través del sacramento de la confesión. Vid. A. SмiтH, The theory of morals sentiments, Oxford, Clarendon Press, 1979 (1759), p. 333. Es más preciso Smith cuando reconoce la verdad de la intuición expuesta reiteradamente por los juristas del Jus Commune, que expresa que la principal fuente de la justicia y de la moralidad es la necesidad. Vid. A. SмITH, Theory..., op. cit., p. 90. Perdió de vista - hecho comprensible en un momento histórico transido del deseo de leyes generalesque donde mejor observamos la necesidad es en los supuestos concretos, pues si el profesor debe explicar con claridad, ello no se deduce desde su buena voluntad o por un contrato concluido con sus alumnos, sino por la necesidad que entraña la docencia. En las discusiones de aquel momento, lord Kames, reclamando más atención hacia lo concreto, destacaba lo poco eficaces que son los conceptos y las teorías generales. Vid. H. Home (lord Kames), Essays on the Principles of morality and Natural Religion, London, 1758, p. 70. Según él, las teorías abstractas son «too sublime and too remote» para mover a los hombres (pp. 83 y 86) y no pasan de ser «castles in the air» (p. 92).

${ }^{81}$ Locke niega la distinción de los powers. Vid. J. LoCKE, «Essay...», op. cit., p. 239.

82 Austin destaca esto reiteradamente. Programáticamente vid. J. Austin, Lectures..., op. cit., p. 34. 
te que no se juega con el dinero. Propongo ser «realista», como Hobbes, y tomar en serio, como si fuera una cuestión económica ${ }^{83}$, la explicación del deber del profesor de explicar claramente.

Los condicionantes, positivos o negativos, que provienen desde las cosas, se le manifiestan claramente. Los que se remiten al ensayo de Heidegger sobre la obra de arte para negar cualquier derecho a las cosas en sede de filosofía práctica debieran ser conscientes de que las bebidas alcohólicas producen un cierto bienestar, pero que también obnubilan el juicio; sabemos con toda certeza que el que está bebido no debe conducir porque existe un nexo de causalidad entre la ingestión de alcohol y la perturbación de las facultades. ¿Es que hay que admitir universalmente la ley de la causalidad, al modo como plantea Kant este problema en su explicación sobre los principios a priori del Entendimiento? Es preciso perder de vista estas cuestiones tan generales: a un jurista le preocupa poco el tema de la validez universal de la ley de la causalidad en los temas físicos; no le preocupa este tema porque carezca de aficiones teóricas o humanistas, sino porque sabe sencillamente, y sin duda alguna, que el alcohol deja en malas condiciones para conducir. Parece más puesto en razón De Andrés cuando indica (en sede de ciencia física pero aplicable parcialmente a la filosofía práctica): «Por muy paradójico que resulte el camino [el que arranca de Descartes], la res cogitans se nos acaba de morir, ya que sólo queda la res extensa [...] $\mathrm{Si}$ el cogito, si pensar, consiste en una pura capacidad racional o formal, pertenece también a la máquina extensa material. En la res extensa hay más logos y capacidad de logos de lo que nunca pensó el racionalismo» ${ }^{84}$.

Estas comprobaciones le llevan a entender la relativa verdad del casuismo práctico. Porque si parte desde la ley de la causalidad, en la generalidad en la que la plantea Hume, comparte las dudas de este filósofo. Pero si se aproxima a su problema concreto como docente - ¿debe preparar las clases?-, las dudas desaparecen. En los casos se manifiestan más claramente las dependencias concretas de las decisiones jurídicas desde los condicionantes y posibilitantes existentes ${ }^{85}$. Es posible que alguien con pre-

${ }^{83}$ Kant proponía invitar a una apuesta a quien creyera estar seguro de algo: «El criterio corriente para distinguir si lo afirmado por alguien es mera persuasión o constituye al menos una convicción subjetiva, es decir, una creencia firme, es la apuesta». I. KANT, Crítica de la razón pura, op. cit., A 824. Hume seguramente no hubiera apostado.

${ }^{84}$ T. De Andrés, Homo cybersapiens. La inteligencia artificial y la bumana, Pamplona, Eunsa, 2002, p. 79.

${ }^{85}$ En ellos aparece más claramente la razón de la tesis de Agazzi: «Si se quieren hacer las cosas con el debido rigor no puede darse lo que se denomina "cálculo puro" si no se "apoya" en alguna evidencia intuitiva, es decir, si no va a remolque de alguna proposición 
venciones hacia lo que los metafísicos llamaban el mundo del ser mire con recelo a lo que es, viéndolo como algo que tiene que superar la libertad humana; a veces es así, pero tengo la capacidad de explicar con libertad ante mis alumnos porque trabajo en la «cosa» de la docencia universitaria. Cuando el investigador se introduce por los campos más amplios que tratan de explicar qué es la justicia, qué es la ley o qué es la interpretación de las reglas generales, pierde seguridad e intuye la profunda razón de John Austin (1830) cuando explicaba que pertenece a la naturaleza de la verdad el ser concreta ${ }^{86}$. Quizá es por esta razón por la que los juristas han sido históricamente tan poco dados a reflexionar sobre las líneas más generales de su trabajo. En la época en la que brilló más alto el Derecho común, sus juristas apenas reflexionaron sobre las estructuras formales de las nociones que estudiaban o que ellos usaban. Hubo que esperar a la guerra que los humanistas montaron contra los juristas, en el Renacimiento, para ver cómo algunos juristas como Conan, Hopper o Bolognettus explicitaron las categorías más generales de lo que ellos hacían ${ }^{87}$.

Los humanistas nos hicieron un flaco favor porque su exigencia del jus in artem redigere hizo que la reflexión jurídica se apartara de las concreciones y que el orden jurídico apareciera como un orden abstracto expuesto en los libros según frases generales. Los romanos y los tratadistas del Derecho común habían dispuesto de técnica suficiente (como mostró el siglo XVI) para componer tratados breves y abstractos sobre el Derecho, pero se abstuvieron de hacer esto porque sabían que la exposición abstracta de los principios jurídicos conllevaba la pérdida de los contenidos de estos principios: Austin reprochaba esto al Código Civil francés ${ }^{88}$, y se burlaba del Allgemeines Landrecht prusiano porque el legislador germano habían dispuesto que los jueces consultaran sus dudas al legislador: en pocos años, el legislador alemán había publicado algo más de treinta volúmenes despejando dudas ${ }^{89}$.

verdadera». Vid. E. Agazzi, La lógica simbólica, Barcelona, Herder, 1986, p. 316, citado por T. DE Andrés, Homo cybersapiens..., op. cit., p. 63.

${ }^{86}$ Vid. J. Austin, Lectures..., op. cit., p. 115. Aquí indica que la naturaleza de la verdad general es distinta que la de la verdad concreta. Tomás de Aquino hizo esta misma distinción e indicó que han de existir dos entendimientos en el hombre, uno que considera las reglas generales y otro que razona con los datos concretos. Vid. T. De Aquino, Liber de veritate Catholicae Fidei..., op. cit., $\$ 1247$.

${ }^{87}$ Sobre la reflexión jurídica de este momento histórico vid. M. J. Rodríguez PuerTo, La modernidad discutida. Iurisprudentia frente a iusnaturalismo en el siglo XVI, Cádiz, Universidad de Cádiz, 1998.

88 Vid. J. Austin, Lectures..., op. cit., p. 670.

${ }^{89}$ Ibid., p. 667. 
Los códigos consiguieron una cierta unificación jurídica nacional, pero la doctrina hubiera podido lograr este mismo resultado de forma menos traumática por estar más adherida a la realidad. El problema que nos ocupa ahora estuvo en que se produjo una cierta Absonderung de los conceptos jurídicos frente al suelo nutricio del Derecho, y esto determinó que hicieran falta dos lógicas paralelas: una que se ocupaba abstractamente del método del Derecho, y otra de la explicación más amplia del Derecho en el conjunto de la vida humana. Los juristas como Puchta o Savigny insistieron en la primera, y los nuevos filósofos y teóricos del Derecho — pensemos en Ahrens, Trendelenburg o Stammler- se ocuparon de la segunda.

Este empeño por explicar con más bases teóricas lo que era cada institución jurídica lo había emprendido John Austin a comienzos del siglo XIX, luego de haberse formado en Alemania bajo Gustav Hugo. Pero Austin no compuso filosofía ni teoría del Derecho según los sentidos que estas expresiones alcanzaron más tarde. Este autor examinó las instituciones jurídicas romanas más importantes, en el campo del Derecho privado, y mostró sus fundamentos, sus conexiones comunes y sus (relativas) posibilidades de relación. Buscaba que el lawyer se convirtiera en jurist gracias al dominio de una base teórica más amplia que la poseían los lawyers de su tiempo $^{90}$, que se formaban en los bufetes de abogados, sin estudios universitarios, y conocían de memoria relaciones de acciones y excepciones con las que complicaban los juicios en demasía porque no estaban en condiciones de argumentar debidamente ${ }^{91}$. Pero la empresa de Austin fue perdida rápidamente, ya que poco tiempo después se impusieron las «Elements of Jurisprudence» de Thomas Erskine Holland, una obra que más bien sienta los fundamentos del Estado, las relaciones del Estado con el Derecho, siempre bajo la visión imperativista de las leyes. No era una obra jurídica en el sentido austiniano y, quizá porque respondía mejor a las nuevas exigencias políticas, obtuvo aparentemente un éxito más rápido y mayor ${ }^{92}$. Indico que su éxito fue parcial porque durante siglo y medio las Lectures de Austin han

${ }^{90}$ Sobre las diferencias entre unos y otros vid. J. M. LightwoOd, The Nature of Positive Law, London, 1883, p. 63.

${ }_{91}$ Thomas E. Holland indicaba que: «In England [...] legal nomenclature is a mosaic of many languages and the law itself, as expounded by Coke and Blackstone, except so far as it has been deduced with much logical, punctiliousnee from the theory of feudal tenure, is little more than a collection of isolate rules». T. E. Holland, The Elements of Jurisprudence, 13. . ed., Oxford, 1924, p. V.

92 James Bryce declaraba que el método de Austin había quedado anticuado. Vid. J. Bryce, «The Methods of Legal Science», Studies in History and Jurisprudence, vol. II, Oxford, 1901, p. 181. 
constituido una ley máximamente normativa para el Tribunal Supremo norteamericano, en medida mucho mayor que la de cualquier otro jurista. Pero ambos, Austin y Holland, fueron incluidos en la Analytical School, y esta denominación común ha cubierto sus profundas diferencias ${ }^{93}$.

\section{PARA TERMINAR}

Hobbes levantó la bandera del «realismo». Seamos realistas nosotros también: la necesidad de tener en cuenta las bases ontológicas se comprueba ante todo en lo concreto; quien entienda que los argumentos que hemos de dar a un estudiante que no estudia, a un ladrón, o al policía que denuncia con demasiada facilidad han de ser argumentos necesariamente distintos, entenderá mejor el planteamiento de este problema.

Desde las comprobaciones de las exigencias de los casos concretos no obtendremos un sistema de ética completo que dé razón de algunos primeros principios de la conducta del hombre y que señale una meta clara para cada vida. Un dicho medieval indicaba que «Ubi desinit ethicus ibi incipit theologus». En efecto, no podemos cargar sobre las espaldas del filósofo del Derecho la fundamentación de diversas reglas generales ni, mucho menos, la orientación de toda la vida. Pero el filósofo del Derecho sí puede preguntarse sobre el carácter personal del ser humano y, en un plano general, debe señalar la contradicción de reivindicar para el hombre algunos derechos que, sin embargo, le son negados en un principio desde bases teóricas empiristas que ya han quedado ampliamente sobrepasadas. En plano más concreto debe reivindicar para cualquier método jurídico la necesidad y el derecho de tener en cuenta las exigencias innegables que arrastra consigo cada situación humana.

Pero queda quehacer para domesticar la experiencia prerreflexiva ${ }^{94}$ que sigue operativa aún hoy fuera ya de sus contextos científicos. A muchos se

93 Allen indicaba que lo más claro de la escuela analítica es que ella componía un movimiento poco claro. Vid. C. K. Allen, Legal duties..., op. cit., p. 13.

${ }^{94}$ Esta frase la tomo del artículo de L. SÁnCHEZ RUEDA, «Segregación o domesticación de la experiencia prerreflexiva», Volubilis, 4 (1996) pp. 35-53. Nadie puede llevar a cabo la caza de brujas que denuncia este autor en la p. 37: «¿No es propio del Logos filosófico, tomado como razón discursiva, un momento de segregación, de expulsión, de la inteligencia prerreflexiva - si es que la hay- como extraña a las exigencias de la lógica de la argumentación, en la que la conciencia reflexiva está consciente a sí misma?». En la p. 38 sitúa más temáticamente la finalidad de su estudio: «El nuevo proyecto de ilustración, que ha llegado a definirse a sí mismo como un proyecto de reconstrucción del Logos socrático, 
les escapa lo no construido, y no pueden admitir que haya un avance en el modo de estudiar las conductas del hombre que no descanse en la creación racional entendida según este modo filosófico creador: han de rechazar cualquier clase de realidad que porte sus propias virtualidades, de modo que ella se desarrolle desde sí misma en la mente del que la estudia. Pero, frente a la mentalidad que sólo entiende de «creaciones», me he referido a mis deberes como profesor, y he indicado que ésta es una de las exigencias que porta en sí la cosa de la docencia, a la que alcanzamos racionalmente sin necesidad de desarrollos especialmente «creativos». Desde luego, a esta mentalidad denunciada le repugna que lo que debiera ser el resultado de su reflexión consista más bien en un «dato» que ha de constituir el inicio de sus razonamientos; de proceder así su racionalismo resultaría superfluo: ¿qué sucedería con la figura del diálogo ideal si Habermas reconociera simplemente este deber de los profesores? Nuestra cotidianidad está repleta de situaciones que portan en sí sus propias medidas: como marido, padre, profesor o ciudadano dispongo de márgenes de discrecionalidad en mis acciones ${ }^{95}$. Desde

parece expulsar toda alianza entre saber y experiencia prerreflexiva al identificar a esta última, bien con una expresión de irracionalidad pura y ciega, bien con una inverosímil aprehensión pura de "lo otro de la razón" que ha sido inventada por las asechanzas del misticismo. Con ello queda negada a priori la posibilidad de una interpenetración productiva entre actos prerreflexivos y actos específicos de la razón. Una concesión en este punto parece poner en juego, una vez más, a la razón misma, cuyo corazón es, como se verá más adelante, de acuerdo con la última generación de la Escuela de Frankfurt, la lógica de la justificación argumentativa».

Esta presentación del problema depende aún de la negación de la racionalidad de los factores que son aparentemente anteriores a la reflexión. Luhmann explicaba que: «Dado que el jurista está acostumbrado a pensar en el interior de instituciones jurídicas singulares». Vid. N. Luhmann, Sistema jurídico y dogmática jurídica, traducción de I. De Otto Pardo, Madrid, CEC, 1983, p. 117.

Los juristas, como nos reprocha Luhmann, tendemos a permanecer en el interior de los problemas, y este hecho, lejos de ser un lastre, es el que nos habilita para situar puntos necesarios de referencia para las actuaciones prácticas. Para Apel y Habermas es irracional aquello que no procede del discurso reflexivo, pero estos filósofos no pueden entender, quizá por seguir implícitamente el consejo de Luhmann, que un discurso práctico reiterativo que sólo gira en torno a la igualdad de los sujetos es un discurso poco racional, porque desde la sola igualdad que se desprende desde la estructura dialógica de la comunicación humana, el profesor no sabe por qué ha de diferenciar las situaciones de explicar en clase y de conducir su automóvil. Son «cosas» distintas cada una de las cuales porta sus propias exigencias de racionalidad. Pues toda institución jurídica ya acabada presenta un momento jurisprudencial que nace desde algunos hechos sociales. Ante un problema (esos «hechos sociales») los juristas proceden a un trabajo de análisis + síntesis, relacionan las reglas que parecen concernir más directamente a esa situación y acaban componiendo una verdadera institución jurídica que normalmente será aceptada por los jueces y por el legislador. Normalmente su aceptación judicial será anterior a su respaldo legislativo.

${ }_{95}$ Extrañamente, Kelsen reconoce la existencia de estos «hechos normativos», tal 
luego, siempre permanecerá en pie lo que Allen llamaba el «átomo irreductible de la voluntad individual» ${ }^{96}$, pero normalmente es inútil tratar de filtrar estas situaciones básicas por la figura omnipresente de un diálogo ideal. Según Austin, estas situaciones constituyen «cualidades», no conjuntos de derechos y deberes ${ }^{97}$. Son hechos desde los que surge el Derecho ${ }^{98}$ porque ellos introducen una cualidad nueva en la cotidianidad.

Si la argumentación sustituye a las argumentaciones porque esta pretendida argumentación única se emancipa de los datos reales de la mano de una exigencia enteramente prerreflexiva del empirismo sobreviviente, comienzan a aparecer las insuficiencias y las contradicciones. Como contradicción suprema siempre permanecerá la que denunciaba Ferguson: que los que niegan la existencia de la conciencia también tienen conciencia ${ }^{99}$. Es difícilmente comprensible mantener un inicio empirista del estudio de la imagen del hombre para declarar después la existencia de un cuasi-noúmeno. Rawls, más en el estilo anglosajón, propuso en un primer momento un individuo egoísta que busca favorecer racionalmente sus intereses; como en este planteamiento está ausente una referencia al deber, más tarde nos animó, en tono vigoroso, a participar cooperativamente en el seno de una sociedad democrática; un discurso propio de predicador dominical. El empirismo vuelve imposible hablar del corazón de la ética, que es el deber. Esta imposibilidad se vuelve a mostrar cuando un autor propone una teoría omnicomprensiva porque es única, es decir, una explicación que solamente reconoce un punto de partida y unas monótonas leyes del desarrollo de las argumentaciones; estamos ante manifestaciones del «pensamiento único». Estas teorías, ya que no doctrinas, nacen fracasadas - a pesar de su amplia audiencia popularporque las raíces de los deberes son plurales. No existe una lex permissiva originaria, como mantenían los discípulos de Kant a comienzos del

como comprobamos en su Reine Rechtslere, op. cit., $\mathbb{\$}$, cuando explica que los actos que se exteriorizan por palabra o por escrito pueden llevar en sí mismos su propia significación (Selbstbedeutung). Pero en lugar de examinar la relevancia de este tipo de situaciones para el derecho hace depender tal Bedeutung del ajuste de esos actos a una norma jurídica. Y cuando se plantea más temáticamente este problema se lanza por los campos de la macroética aludiendo a la imposibilidad de derivar normas prácticas desde la naturaleza inmutable o desde Dios creador de la naturaleza.

96 Vid. C. K. Allen, Legal duties..., op. cit., p. 112.

97 Ibid., p. 697.

${ }_{98}$ Ibid.,pp. 700-701.

99 Vid. A. Ferguson, Un ensayo sobre la historia de la sociedad civil, traducción de J. Rincón, Madrid, IEP, 1974 (1777), p. 42. En la literatura jusfilosófica es raro encontrar denuncias que destaquen expresamente estas contradicciones. 
siglo XIX ${ }^{100}$, ni una lex constrictiva originaria, como parece mantener Kelsen con la función que otorga a la categoría lógica del Sollen. Ninguna de estas dos figuras lógicas alcanza a explicar por qué el profesor debe corregir los exámenes con equidad o por qué debe tener libertad para elegir la enseñanza de sus hijos. Si perdemos de vista las determinaciones del día a día, nos perderemos en las discusiones academicistas que levanta cada teoría ética que agrada al público.

Cabe preguntarse si este volver a recuperar después lo que en un inicio fue declarado falso o incapaz es una contradicción soportable que hace honor a la complejidad de la realidad. ¿Estamos ante personas de espíritu amplio y elástico capaces de dar razón de las contradicciones porque saben contradecirse sin desdecirse, o estamos ante recursos retóricos que denotan falta de creatividad e insuficiencia de sus axiomas y de sus reglas de inferencia? Parece que si se propone como sistema de ética un conjunto lógico que parte desde una base empirista, y que para ello es imprescindible declarar equivocadas las éticas existentes que están fundamentadas ante todo en manifestaciones del sentido para la justicia, no es lícito volver a recuperar aquello cuya imposibilidad componía la principal razón de ser del nuevo método propuesto. No parece correcto despojar a los seres humanos de su personalidad para, en un segundo momento, negar la individualidad en nombre de la personalidad (colectiva) ya desdeñada antes ${ }^{101}$.

Este tipo de aperturas de espíritu son posibles en un sistema ético del tipo del aristotélico, que juega en todo momento con un combinado de relatives de distinta procedencia y diferente estatuto epistemológico y ontológico, por lo que renuncia a la exactitud lógico-científica según el estilo moderno: Michel Bastit ha reeditado recientemente algunas

\footnotetext{
${ }^{100}$ Vid. mi estudio La Cabeza de Jano, Cádiz, Universidad de Cádiz, 1989, pp. 21 y ss., y 43 y ss.

${ }^{101}$ Los sistemas éticos pretendidamente científicos, desde sus bases conductitas o behavioristas, optan por la individualidad a costa de la personalidad. Frankl nos indica que: «¿Cuáles son las razones que llevan al psicólogo con ceguera para la autotrascendencia y, consecuentemente, para la captación de sentidos y razones? Si es un psicoanalista, querrá sustituir los motivos por ciertas tendencias e instintos como causas de la conducta humana. Si es un behaviorista, querrá ver en la conducta humana el mero efecto de los procesos de condicionamiento y aprendizaje. Si no existen sentidos, ni razones, ni elecciones, deben suponerse otros determinantes, de una manera u otra, para reemplazarlos. En tales circunstancias, la condición misma de humanidad se deja de lado en la observación de la conducta humana. Si la psicología o, en este caso, la psicoterapia, ha de ser rehumanizada, debe hacerse siendo conscientes de la autotrascendencia más bien que ignorándola». V. FrANKL, La idea psicológica del hombre, Madrid, Rialp, 1979, p. 29.
} 
tablas lógicas clásicas ${ }^{102}$, precisamente porque este sistema de lógica abre la posibilidad de lograr este juego en el que se combinan en cada caso una cierta cantidad heterogénea de principios con relevancia normativa. Tomás de Aquino consideraba que la ira es uno de los pecados más graves: uno de los «pecados capitales» según la teología moral. Pero, se plantea él, ¿es bueno dejar llevarse por la ira? No solamente es bueno, sino necesario, porque si un hombre no reacciona airadamente cuando es agraviado, y especialmente cuando es agraviado personalmente, ese hombre deviene triste, y la tristeza es el peor mal, que hace que el hombre pierda hasta su propia naturaleza ${ }^{103}$. Resulta patente que el de Aquino afirma al hombre sobre las argumentaciones morales, y no lo hace mediante desarrollos lógicos desde un principium fundamentador básico, sino desde las manifestaciones vitales de la cotidianidad: una de esas manifestaciones de la humanidad que hace que el profesor se sienta en el deber de llevar su auto prudentemente.

Para terminar de alguna forma elegante, entre las varias maneras posibles y justificadas de abandonar ahora este tema, parece que el problema aludido se ha nos planteado ante todo por la afirmación de la función omniabarcante de la conciencia objetiva que es propia de la geometría. Ya indiqué que hemos de contar necesariamente con la sintaxis que impone la mecánica clásica porque las formas argumentativas más básicas de este modo de entender la mecánica se han convertido en patrimonio universal durante estos últimos cuatro siglos; pero ya existen razones también científicas para superarla cuando sea el caso. Descartes se representó un espacio plano (parece ser el mismo de Einstein cuando propone el ejemplo de la cama elástica), y cabe acusarlo ante el tribunal de la razón de haber polarizado gratuitamente este espacio así concebido. Era un espacio sin relieves, que no conocía más que las ubicaciones de arriba-abajo, izquierda-derecha y adelante-detrás, ubicaciones en rigor irrelevantes para ellos porque la formación de la realidad, según esta mentalidad, habría sido fortuita, violenta y amoral. De acuerdo con la visión mecánica subyacente, todos los problemas — también los del hombrese resolverían en una cadena prácticamente infinita de causas y efectos en el sentido indicado, según el mos geometricus. Frege y Peano se esforzaron por mostrar los fundamentos lógicos de las matemáticas, y

102 M. Bastit, Tables de logique. Sur l'Introduction de Porpbyre, les Catégories, l,'Interprétation et les Premiers Analytiques d'Aristote, Paris-Budapest-Torino, L'Harmattan, 2003.

${ }_{103}$ Vid. T. De Aquino, Liber de Veritate Catholicae Fidei..., op. cit., $\$ \$ \$ \$ 801$ y 805. 
Gödel demostró matemáticamente que todo conjunto axiomático suficientemente completo supone necesariamente factores que no se pueden demostrar desde tal conjunto axiomatizado y que no se contienen en él. Pero el espacio único y plano cartesiano hace irrelevantes estas dificultades ante el gran público: en él, todos los gatos son pardos, y tanto podemos ir de atrás a adelante como de adelante a atrás, como si la degeneración necesaria - la entropía- no existiera. El sentimiento o la vivencia de este único espacio de discusión (llamado espacio humano y por eso tiene un toque especialmente humanista) constituye una capa que encubre una multitud de miserias. 